\title{
Fully Mediated Effects of Formative Measures Using MIMIC Constructs
}

\author{
James J. Jiang \\ School of Accounting and Business Information Systems \\ The Australian National University \\ Canberra, ACT 0200 Australia \\ james.j.jiang@anu.edu.au \\ Jacob C. Tsai \\ School of Accounting and Business Information Systems \\ The Australian National University \\ Canberra, ACT 0200 Australia \\ homeanking@gmail.com \\ Gary Klein \\ College of Business Administration \\ The University of Colorado Colorado Springs \\ 1420 Austin Bluffs Parkways \\ Colorado Springs, CO 80933-7150, USA \\ gklein@uccs.edu \\ Stacie Petter \\ Information Systems \& Quantitative Analysis \\ College of Information Science \& Technology \\ University of Nebraska at Omaha \\ 1110 S 67 th St \\ Omaha, NE 68182-0392, USA \\ spetter@mail.unomaha.edu
}

\begin{abstract}
Formatively-measured constructs are increasingly applied in information system research models. Recent work shows that exogenous formatively-measured constructs suffer from a number of problems that include interpretational confounding and a lack of external consistency. Yet replacement by reflectively-measured constructs can lead to bias if not theoretically appropriate. One solution may be to use a MIMIC construct composed of the formative measures as well as two additional reflective measures. A simulation study indicates that a MIMIC so composed mitigates the problems of interpretational confounding and poor external consistency allowing use broader use in a variety of structural models.
\end{abstract}

Keywords: Formative measures, endogenous variables, research methodology, structural equation models, simulation, MIMIC models 
Fully Mediated Effects of Formative Measures Using MIMIC Constructs / Jiang et al.

\section{Introduction}

Formatively-measured constructs increasingly appear in the information systems (IS) literature both in terms of application in research models and concern for methodological issues (Petter et al., 2007; Kim et al., 2010; Diamantopoulos, 2011; Bagozzi, 2011; MacKenzie et al., 2011; Bollen, 2011; Treiblmaier et al., 2011). Formativelymeasured constructs differ from reflectivelymeasured constructs in that the observable items comprising formative measures are considered causes of a latent variable while reflective items are considered observable consequences of a latent variable. Though formative measures hold potential value in building research models, concerns about their use in theory testing and structural equation modeling (SEM) abound, particularly in consideration of formative exogenous variables (Wilcox et al., 2008; Franke et al., 2008; Kim, et al., 2010; Diamantopoulos, 2011; Bollen, 2011; Treiblmaier et al., 2011). The essential question was posed by Wilcox, et al. (2008, p.1219) who stated "... reflective measurement has filled the role of creating measures of constructs that can be used in different studies by different researchers to test different theories. But can formative measurement fill the same need? Does formative measurement allow researchers to use the same 'off-the-shelf' measure in different contexts to test different theories?"

In order to confidently use formativelymeasured constructs in the same fashion that researchers have employed for reflectivelymeasured constructs, one must overcome known concerns about formative measures. As research investigates formative measurement, many concerns have been addressed while others still require further examination and resolution (Diamantopoulos et al., 2008; Diamantopoulos, 2011; Bagozzi, 2011; MacKenzie et al., 2011; Bollen, 2011). Known challenges when employing formativelymeasured constructs in a research model include vulnerability to multicollinearity, the requirement for emanating paths from the formatively-measured construct for model identification, and an inability to validate the construct with techniques commonly employed for reflectively-measured constructs. Past work has examined these issues, though not all researchers are content with the idea of formative measurement (Diamantopoulos et al., 2008). Of continuing concern are issues of interpretational confounding and a lack of proportional structural effects when used as an exogenous variable (Franke, et al., 2008; Kim, et al, 2010). Interpretational confounding occurs "as the assignment of empirical meaning to an unobserved variable which is other than the meaning assigned to it by an individual a priori to estimating unknown parameters. Inferences based on the unobserved variable then become ambiguous" (Burt, 1976, p.4). Proportional structural effects are preserved when the construct functions as a point variable such that measures correlate with other constructs in proportion to their correlation with their own construct. This implies that a formatively-measured construct must fully mediate the effects of its measures in order to be representative (Franke, et al., 2008).

In IS research models, the inclusion of a formatively-measured construct as an antecedent can lead to both interpretational confounding and inconsistent proportional structural effects (Kim, et al., 2010; Bagozzi, 2011; MacKenzie et al., 2011). Researchers in other disciplines also report these issues (Franke et al., 2008). To counter these and other possible problems with formativelymeasured constructs, a technique gaining ground among some researchers is the Multiple Indicators Multiple Causes (MIMIC) construct created by adding two reflective items to any variable measured formatively (Diamantopoulos and Winklhofer, 2001; Diamantopoulos et al., 2008; Bagozzi, 2011; Diamantopoulos, 2011). Whether the MIMIC modeling guidelines can address issues of interpretational confounding and structural proportionality has not been explored in the literature. The purpose of this study is, therefore, to examine whether a MIMIC model reduces interpretational confounding and exhibits consistent proportional structural effects for exogenous formatively-measured constructs. 
Consistency of weights of the formative measures, parameter estimates for structural paths, and mediation of the formative measures are examined with simulation techniques to consider whether the MIMIC model can limit these crucial problems for formatively-measured constructs.

\section{Background}

Information system scholars have adopted structural equation modeling (SEM) as a common technique to investigate theoretical models of interest (Petter et al., 2007; MacKenzie et al., 2011; Bollen, 2011). Structural relationships are proposed among latent variables and tested by either covariance based techniques or component based techniques (Fornell and Bookstein, 1982). The latent variables are measured by observable measures that measure the unobservable variable (Borsboom et al., 2003). The argument is that any change to the latent variable will also occur to the measures. Most commonly, researchers view that interventions that change the latent variable can be detected by endogenous measures (Coltman et al., 2008). This relationship is termed reflective, a consideration of the change in each measure being a reflection of the change in the latent variable. Causality is implied from the variable to the measures and the measures are understood to be positively correlated (Bollen, 1989).

From a theoretical view, however, it is just as conceivable that a variable is formed by multiple measures that are not correlated with each other (Blalock 1964; Diamantopoulos and Winklhofer 2001; Edwards and Bagozzi 2000). This is termed a formativelymeasured construct. Causality is presumed to flow from the measures to the latent variable. Further, formative measures in a construct need not covary (Bollen and Lennox, 1991), and hence may not have the same antecedents, consequences, or relationships to other variates (Jarvis et al., 2003). If any formative measure increases, the latent variable increases even if all the other measures remain stable. This implies that if the latent variable increases, not all measures in a formatively-measured construct need to increase unlike in a reflectively-measured construct where all reflective measures are assumed to change accordingly.

Reflectively-measured constructs with items seen as outcomes of the latent variable have been popular in the IS literature for many years in some of the more common models (Petter et al., 2007). As an example, the original Technology Acceptance model contains a latent variable in the structural equation model called ease of use (Davis, 1989). If a system is perceived to be easy to use, there will be expectations of the system that reflect such a perception (easy to learn, controllable, clear and understandable, flexible, easy to become skillful, easy to use). The items should all be related in order to add to consistency and reliability of the construct plus are part of the nomological net of the theory since they are direct consequences of the latent variable. On the other hand, formative items causing the latent variable in the construct need not be part of the same nomological net nor necessarily correlated with one another (Bollen and Lennox, 1991; Diamantopoulos and Winklhofer, 2001). For example, governance characteristics in outsourcing contracts are formed by the presence of distinct clauses in the contract that include a communication plan, a measurement charter, a conflict resolution charter, and an enforcement plan (Goo et al., 2009). These items need not be correlated among themselves, could come from different sources and/or different nomological nets, and should completely define the latent variable as we understand it. These are components that come together to form the latent variable rather than being observed consequences of having governance clauses in a contract.

Figure 1 shows a formatively-measured construct with three measures. The measures (xi) may or may not be correlated ( $\Phi \mathrm{ij})$. Each is related to the latent variable $(\eta)$ with a path coefficient ( $\mathrm{\gamma i}$ ). The latent variable is thus formed as a linear combination of the measures such that: 


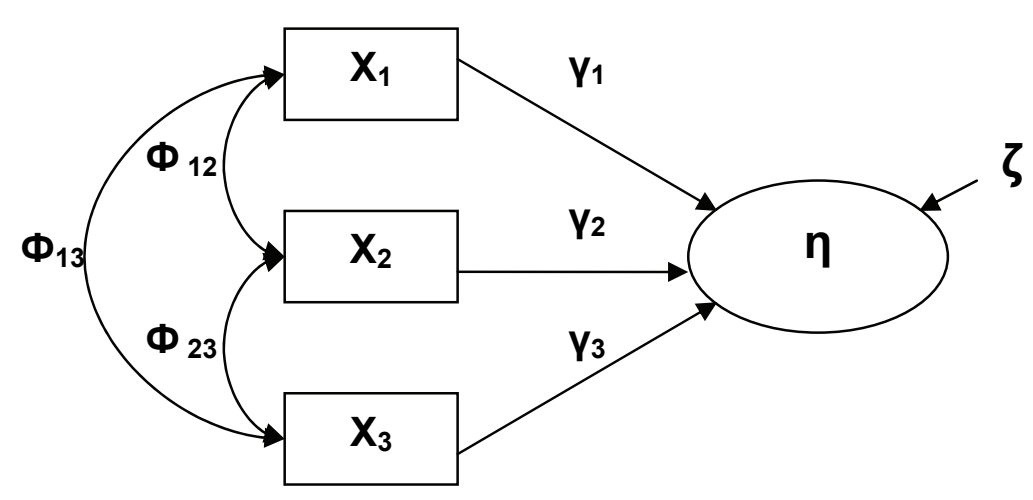

Figure 1 - Formatively-measured construct

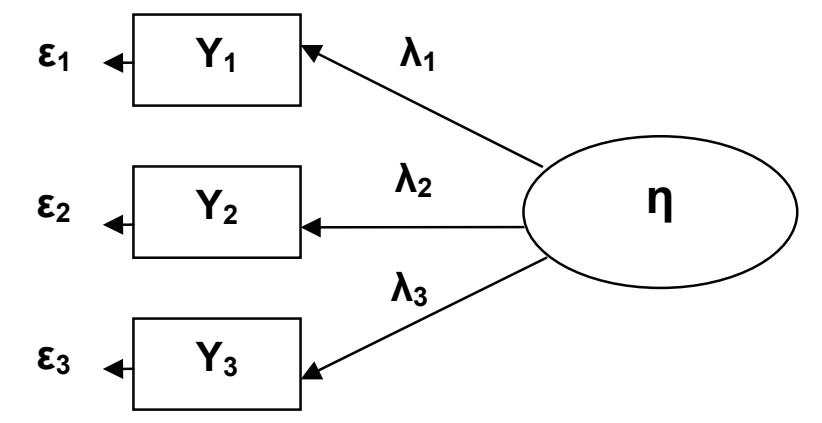

\section{Figure 2 - Reflectively-measured construct}

Eq. 1: $\eta=y_{1} X_{1}+\gamma_{2} X_{2}+y_{3} X_{3}+\ldots+y_{n} X_{n}$ $+\zeta$

This differs from reflectively-measured constructs where each measure has a separate linear relation with the latent variable as shown in Figure 2 with the equation appearing:

Eq. 2: $Y_{i}=\lambda i^{*} \eta+\varepsilon_{i}$

where $\mathrm{Yi}$ is the ith reflective measure, $\lambda \mathrm{i}$ is coefficient representing effect of latent variable on measure, $\eta$ is reflectively-measured construct, and $\varepsilon \mathrm{i}$ is measurement error for reflective measure i.

Rather than having an error term for each measure as in the reflectively-measured construct, the formatively-measured construct has a single error term ( $\zeta)$. This error is considered to represent the impact of all remain- ing causes not represented by the measures included in the construct (Diamantopoulos, 2006; 2011). Given this interpretation of the error term, as long as all possible causes of the latent variable are included in the construct, the error term could be excluded. However, when not all possible causes are explicitly incorporated as formative measures (which is common in practice), the error term must be included as a parameter and estimated along with the other parameters to ensure correct model specification.

Recent papers have examined the IS literature to determine the pervasiveness of formatively-measured constructs and concluded their use is expanding (Petter et al., 2007; Kim et al., 2010). Appendix A indicates the papers that have employed formative measures in a SEM study from 2009 through 
2011 in the six core MIS journals (Management Information Systems Quarterly, Information Systems Research, Journal of the Association for Information Systems, Journal of Management Information Systems, European Journal of Information Systems, and Information Systems Journal). In all, 50 papers have used formative measures compared to 133 papers in the same period that employ only reflectively measured constructs. The fact that a high incidence of MIS research in recent years in the top six journals has used formatively-measured constructs suggests the increasing popularity of this form of measurement. Therefore, it is important to address the use of formative measurement in SEM studies. Furthermore, of the 109 formatively-measured constructs, 63 of them (58\%) were exogenous variables within the research model. Our focus in this article is limited to formative constructs as exogenous variables as the issues differ from formative constructs as endogenous variables (MacKenzie et al., 2005).

Reasons for employing formatively-measured constructs in research include increased explanatory power and avoidance of misspecification bias. Formatively-measured constructs are unique because they represent latent variables perceived to be composites of specific components (Edwards and Bagozzi, 2000). This presents unique opportunities for the interpretation of results where changes to the latent variable have measures that might predict the change. Should the latent variable be one of interest to practice, reflective items present no guidance as to how to alter the variable of interest since they occur as a result of change to the latent variable. Formative items, however, allow researchers to legitimately draw advice from the relationship of the measures. Incorrectly specified directionality, in either direction, can lead to extreme bias in the estimate of structural parameters, even to the point of indicating relationships are significant when they in fact are not (MacKenzie et al, 2005; Petter et al., 2007; MacKenzie et al., 2011).

However, formatively-measured con-structs present a number of issues that must be re- solved prior to their incorporation in SEMbased research. Specification of the construct requires the items be distinct from the latent variable, the items covary with the latent variable, temporal conditions hold, and rival explanations are eliminated (Edwards and Bagozzi, 2000). The latter condition is a major argument as to why formative items must be a complete set, fully explaining the latent variable without omission of any actual causes. Failure to include any relevant facet of the variable alters the content domain and excludes part of the construct itself resulting in conceptual and theoretical changes to the structural model (Diamantopoulos and Winklhofer, 2001; Diamantopoulos, 2011). Inclusion of a large number of measures potentially results in multicollinearity problems that must be addressed through item purification procedures (Bollen and Lennox, 1991; Diamantopoulos and Winklhofer, 2001; Diamantopoulos, 2011). Formative latent variables are under identified in SEM without having at least two emitting paths (MacKenzie et al., 2005). Of more recent concern in the IS literature is issues associated with interpretational confounding (Kim et al., 2010) and proportional structural effects (Franke et al., 2008). For the remainder of the paper we focus our attention on these concerns. In particular, our focus in this article is limited to exogenous formatively-measured constructs as the issues differ from endogenous formativelymeasured constructs (MacKenzie et al., 2005).

\section{Interpretational Confounding}

The nominal meaning to a construct is assigned without reference to empirical information. The construct's empirical meaning derives from its relations to one or more observed variables in an experimental setting. Empirical meaning applies to both the construct itself and to its relationships to observable measures of other constructs in a structural model. Interpretational confounding occurs "as the assignment of empirical meaning to an unobserved variable which is other than the meaning assigned to it by an individual a priori to estimating unknown parameters. Inferences based on the unobserved variable 
Fully Mediated Effects of Formative Measures Using MIMIC Constructs / Jiang et al.

then become ambiguous and need not be consistent across separate models" (Burt, 1976, p.4).

Interpretational confounding is evident when the coefficients linking measures and the latent formative variable significantly change with changes to the endogenous variables in a model or when the path coefficient from the latent formatively-measured construct to an endogenous variable changes if another endogenous variable is replaced (Bollen, 2007; Howell et al., 2007; MacKenzie et al., 2011). In the former case, the change to the coefficients of the formative items indicates that the meaning of the items as part of the measurement construct differs from any meaning later attached to the items in a structural model. In the latter case, the measurement model is inconsistent in structural model applications, furthering interpretational confounding in the current study and making comparison across studies problematic. In Figure 3 , the value of $\mathrm{y} 13, \mathrm{y} 13$, and $\mathrm{y} 13$ depend on the relationships to the variables $\eta 2$ and $\eta 3$. Changing out $\eta 3$ for another endogenous variable possibly changes the values of $\gamma 13, y 13, \gamma 13$, and $\beta 12$ showing how the structural model and measurement model are related with a formative exogenous variable. Since the dependent variable in Eq. 1 is latent, the downstream variables are necessary to estimate the coefficients on the paths form the formative items to the latent variable in a formatively-measured construct. Studies have demonstrated that the nature of the latent construct depends on the dependent constructs included in the model (Kim, et al., 2010; Howell, et al., 2007; Hardin et al., 2008a; Hardin et al., 2008b; MacKenzie et al., 2011).

\section{Proportional Structural Effects}

Proportional structural effects state that the measures "must have effects on the outcomes that are proportional to their effects on the formatively-measured construct itself" (Franke et al. 2008, p 1229). This has a direct impact on external consistency, which is realized when the items measuring the con- struct have a similar relationship to the antecedents and consequences as to the construct itself. In other words, external consistency is lacking if items of a formativelymeasured construct have different relationships with the endogenous variables than the formative latent construct itself (Blalock, 1969; Bollen and Davis, 1994; Hayduk, 1987). Recent studies have demonstrated the lack of point variability of the traditional formativelymeasured construct (Kim et al., 2010; Franke et al., 2008).

External consistency is usually defined as a preservation of the ratios of the correlations of the items to the latent variable and the items to the measurement items of other variables in the model (Anderson and Gerbing, 1982). This is considered similar to the concept of a point variable where the latent variable is expected to serve as a single point in relationships to other variables in the model (Howell et al., 2007). The implications of a point variable are that the structural proportion of the measures to their latent variable as to other variables, meaning that a formativelymeasured construct fully mediates the effects of its measures on other variables (Blalock, 1969; Bollen and Davis, 1994; Hayduk, 1987; Diamantopoulos, 2011). The presence of structural proportionality is a sufficient, but not necessary, condition for external consistency (Anderson and Gerbing, 1982).

Figure 4 shows a set of possible relationships in a model with one formatively-measured construct as an antecedent to two reflectivelymeasured constructs. If $\eta 1$ mediates the relationships of its measures to $\eta 2$ and $\eta 3$, then the proportional structural effects ensure external consistency exists for the formativelymeasured construct. In other words, in Figure 4 , there should not be a direct effect between any $X 1 \mathrm{j}$ and $\eta 2$ or $\eta 3$. All $\beta 1 \mathrm{jk}$ should be close to zero. This premise is assumed in previous discussions and applications of formative models but not demonstrated to hold (Diamantopoulos, 1999; 2011; MacCallum and Browne, 1993). 

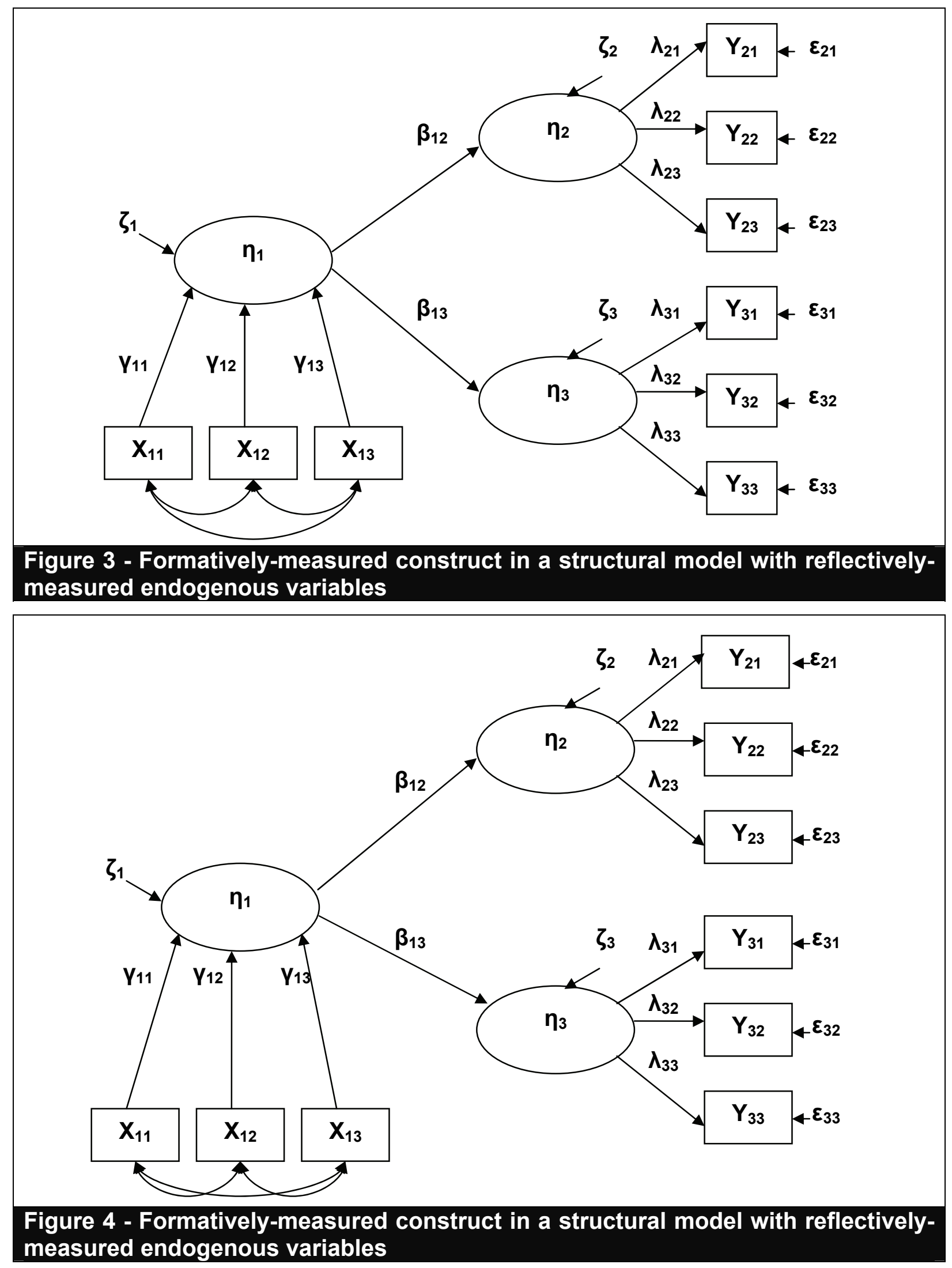
Fully Mediated Effects of Formative Measures Using MIMIC Constructs / Jiang et al.

\section{The Mimic Construct}

The Multiple Indicators Multiple Causes (MIMIC) construct is created by adding two reflective items to any variable measured formatively (Diamantopoulos and Winklhofer, 2001). Such a construct is one of the choices for fully specifying formatively-measured construct which requires two emitted paths, the other being two reflectively-measured constructs, or one reflectively-measured construct and one reflective item (Jarvis et al., 2003; Diamantopoulos et al., 2008; Diaman- topoulos, 2011). Figure 5 shows a MIMIC construct. The idea behind the MIMIC construct is to allow complete specification of the formative measures so that they need not be dependent on the other constructs in a SEM study. This allows separation of measurement and structural issues that formativelymeasured constructs do not otherwise permit. The construct could replace formativelymeasured constructs in a SEM. Doing so for the model in Figure 3 would result in the model of Figure 6.

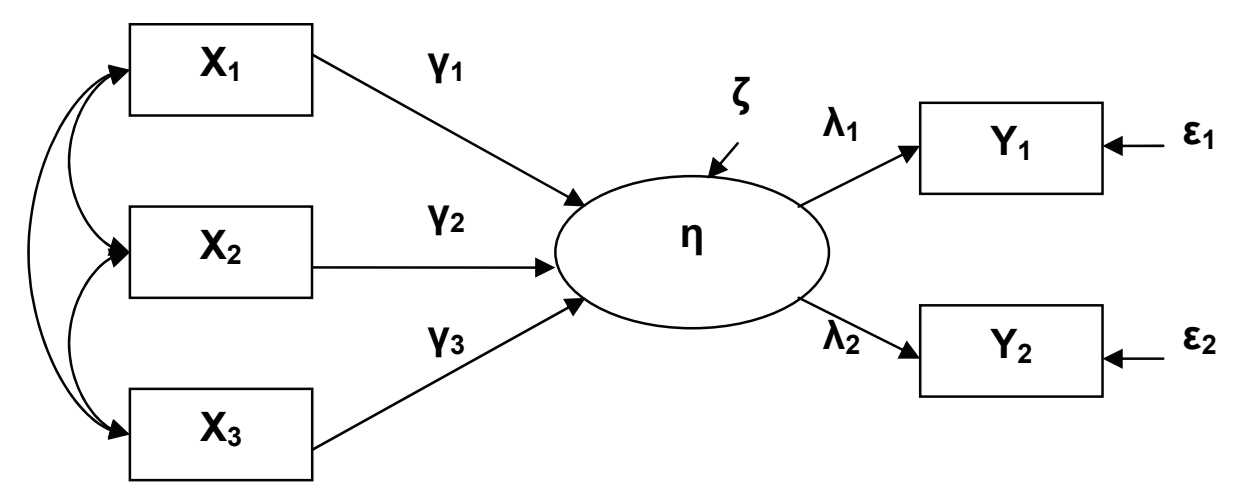

Figure 5 - A MIMIC construct with three formative measures $\left(X_{i}\right)$ and two reflective measures

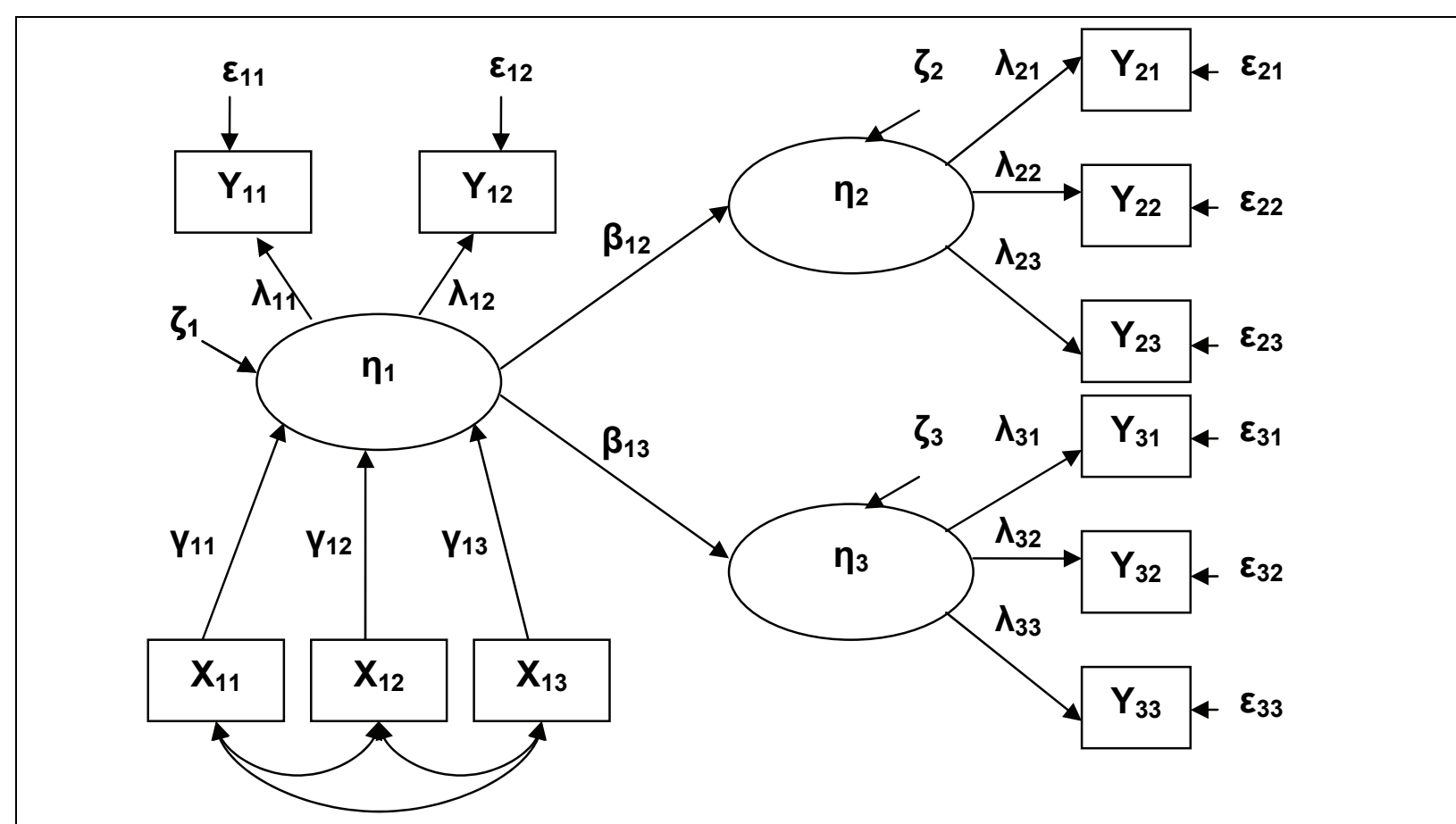

Figure 6 - A MIMIC construct in a structural equation model 
Fully Mediated Effects of Formative Measures Using MIMIC Constructs / Jiang et al.

The MIMIC construct still requires a complete set of formative predictors, but is considered to address issues of interpretational confounding and external consistency (Jarvis et al., 2003; MacKenzie et al. 2005; Diamantopoulos et al., 2008; Diamantopoulos, 2011). Consider the model in Figure 7 where all direct paths to the dependent reflectivelymeasured constructs are shown. The underlying reason to use a MIMIC formativelymeasured construct is to completely mediate the effects of the formative measures on other variables (Franke et al., 2008). If the formative measures have direct as well as indirect (partially mediated) effects on the outcome variables, then the proportionality constraint would not necessarily hold and external consistency could not be established, calling the meaning and value of the formative conceptualization into question.
In order to demonstrate whether a MIMIC model is a full mediator, one needs to show the direct impact of each Xij on $\eta \mathrm{k}$ (where $\mathrm{k}=$ 2 or 3 ) is zero in the model of Figure 7. Likewise, the direct impact of each $\mathrm{Xij}$ on $\eta \mathrm{k}$ (where $\mathrm{k}=2$ or 3 ) in Figure 8 would be identical to the indirect impact of $\mathrm{Xij}$ on $\eta \mathrm{k}$ (where $k=2$ and 3 ). In Figure 8, for example, the estimated value of $\beta 112$ would be equal to the estimated value of $\mathrm{Y} 11+\beta 12$ in Figure 6. As Franke et al. (2008) and Aguirre-Urreta and Marakas (2012) noted, the scaling used for a formative construct can reveal instability in the construct. Scaling occurs in covariance-based SEM when a path in the measurement model is set to 1 for identification purposes. In a MIMIC model, the path that is set to 1 would be one of the reflective measures as it is a unidimensional measure of the construct, thus mitigating the variation in proportional effects.

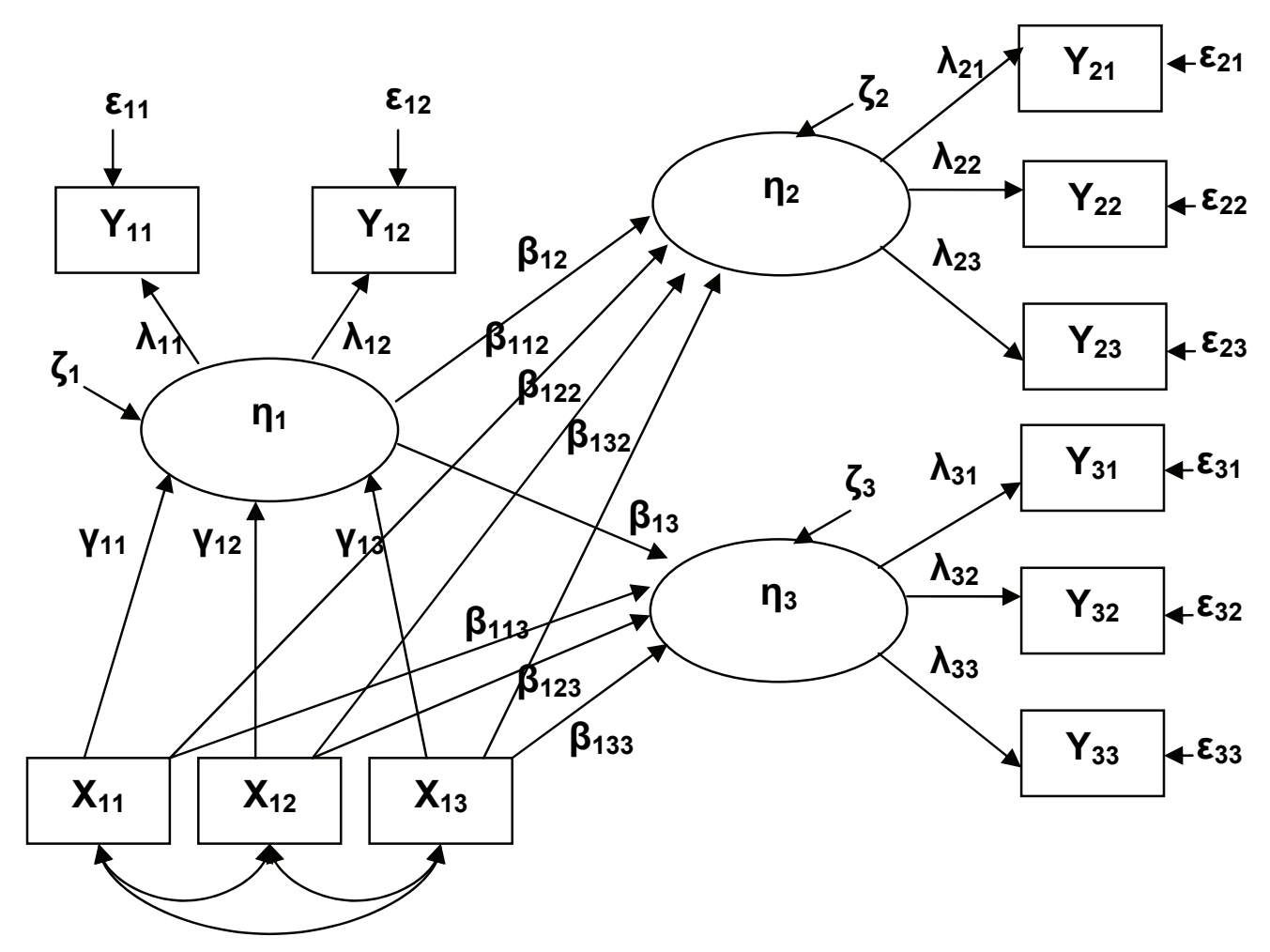

Figure 7 - MIMIC construct with relationships from the formative measures to the endogenous variables 


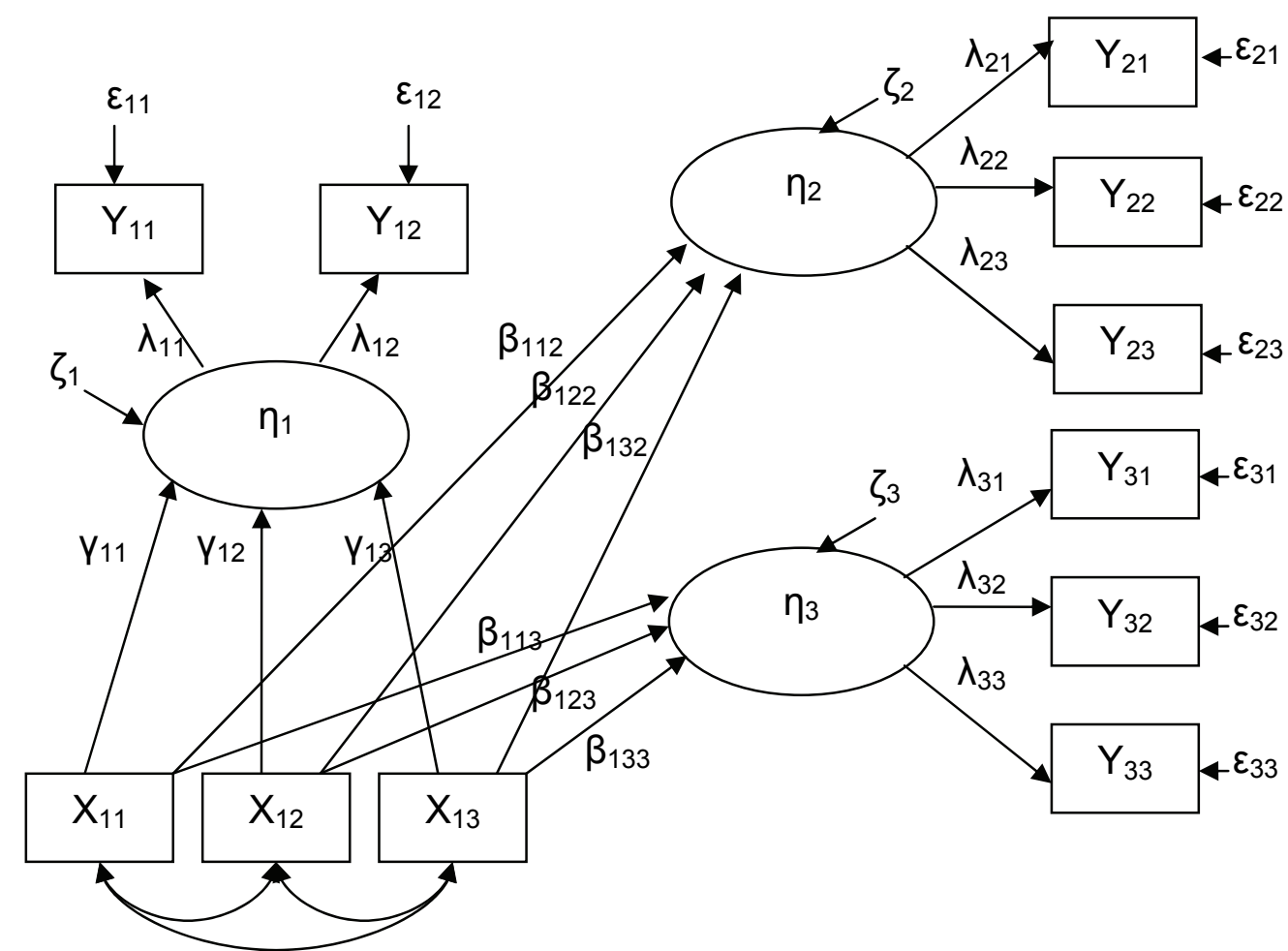

Figure 8 - Depicts a set of the formative measures lead to two outcomes variables directly

\section{Simulation}

We conducted a Monte Carlo simulation to examine the issues of interpretational confounding and proportional structural effects. The models of the simulation test for interpretational confounding by examining the stability of the path coefficients when changing the dependent variables. Figure 9 shows the assumed "true" relationships as specified in the simulation. ${ }^{1}$ The effectiveness of the forma-

\footnotetext{
1 The values chosen for the "true" relationships are generally consistent with the weights and structural parameters in Kim et al. (2010). The model used to generate the covariance matrix for the measurement and structural estimates shown in Figure 9 was actually a single model that included the MIMIC construct for $\eta_{1}$, and three endogenous variables $\left(\eta_{2}, \eta_{3}, \eta_{4}\right)$. When performing the actual simulations, only a subset of this generated covariance matrix was used based on the model tested. The reason for combining the four constructs in a single model for generating the original covariance matrix for simulation was to ensure that the covariances for the formatively-measured construct (and MIMIC construct) were consistent throughout all simulations and did not introduce any bias when a different endogenous variable appeared in the model.
}

tive latent variable as a mediator is also examined using the simulation results to establish whether a MIMIC construct serves as an effective point variable for purposes of proportional structural effects, thereby external consistency.

\section{Simulation Models}

To evaluate the ability of a MIMIC construct to reduce interpretational confounding, we compare the Base Model to Model $\mathbf{A}_{\mathrm{cv}}$. The base model uses a traditional formativelymeasured construct that has paths to two endogenous, reflectively-measured constructs. Model $A_{C V}$ includes the addition of two reflective items for the formatively-measured construct, thus creating a MIMIC model for the formatively-measured construct. By comparing the stability of the formative measure weights and parameter estimates across the Base Model and Model $A_{C v}$ when the endogenous variables change (i.e., from $\eta_{3}$ in Figure $9 a$ to $\eta_{4}$ in Figure $9 b$ ), we can assess if a MIMIC construct can address the concern of 
interpretational confounding for formativelymeasured constructs.

To examine external consistency, this simulation separated the total effects into indirect and direct effects to demonstrate the magnitude of the mediating effect of the formative latent variable (i.e., $\eta_{1}$ ). The mediating effect of formative MIMIC model was examined by calculating and comparing the indirect and direct effects of its formative measures on the different sets of endogenous constructs. We used two reflective endogenous constructs $\left(\eta_{2}\right.$ and $\left.\eta_{3}\right)$ as an example and depicted the specified models (Model $A_{C V}$, Model $B_{C V}$ and Model $\mathrm{C}_{\mathrm{CV}}$ ) in Figure 10. Model $\mathbf{A}_{\mathrm{cv}}$ only allowed the formative MIMIC construct to have direct links to two endogenous constructs and is identical in structure to the model of Figure
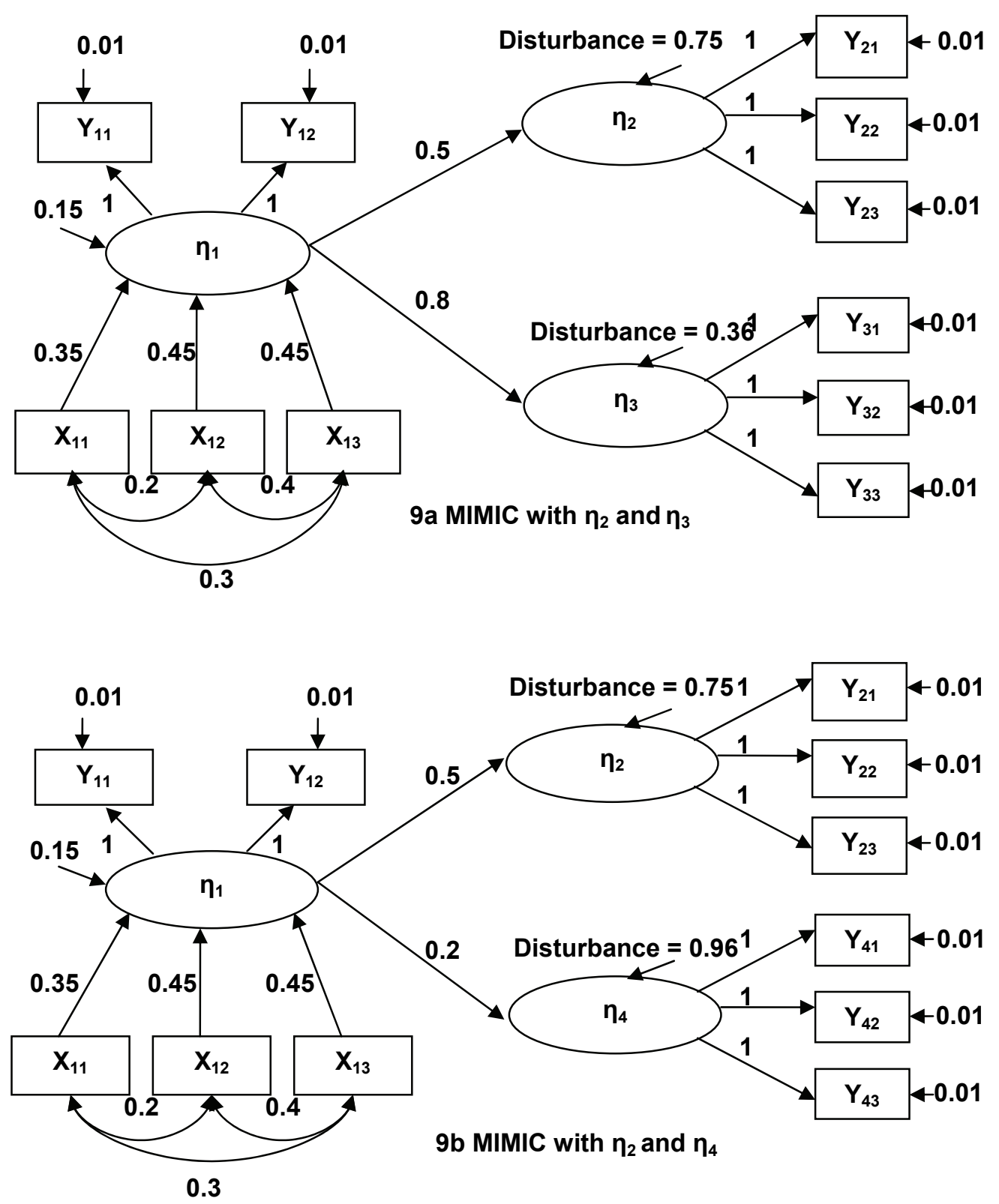

Figure 9 - True parameters model in covariance-based software 
Fully Mediated Effects of Formative Measures Using MIMIC Constructs / Jiang et al.

9a. Model $\mathbf{B}_{\mathrm{cv}}$ allowed the formative MIMIC construct and its formative measures both to have direct links to the same two endogenous constructs. Model $\mathbf{C}_{\mathrm{cv}}$ only allowed the formative measures to have direct links to the same two endogenous constructs. The same sequence was repeated for two reflective endogenous constructs $\left(\eta_{2}\right.$ and $\left.\eta_{4}\right)$.

\section{Assumptions}

The parameters of the models are shown in Figure 9. The weight of formative measures was set to $0.35,0.45$ and 0.45 . We assume a small error term for the formatively- measured construct $(0.15)$ and all formative measure coefficients are significant, indicating a sound formative measure (Diamantopoulos, 2006). All reflective items have very low errors in defining the latent variables (0.01) to ensure the results are not influenced by poor reflective measures. The structural path between the formative MIMIC construct and $\eta_{2}$ remained at 0.5 for all runs, while the path to $\eta_{3}$ was 0.8 and the path to $\eta_{4}$ was 0.2 . Changing from 0.8 to 0.2 in the path model for the second reflectively-measured construct should induce changes to estimates in the paths from the formative measures to the
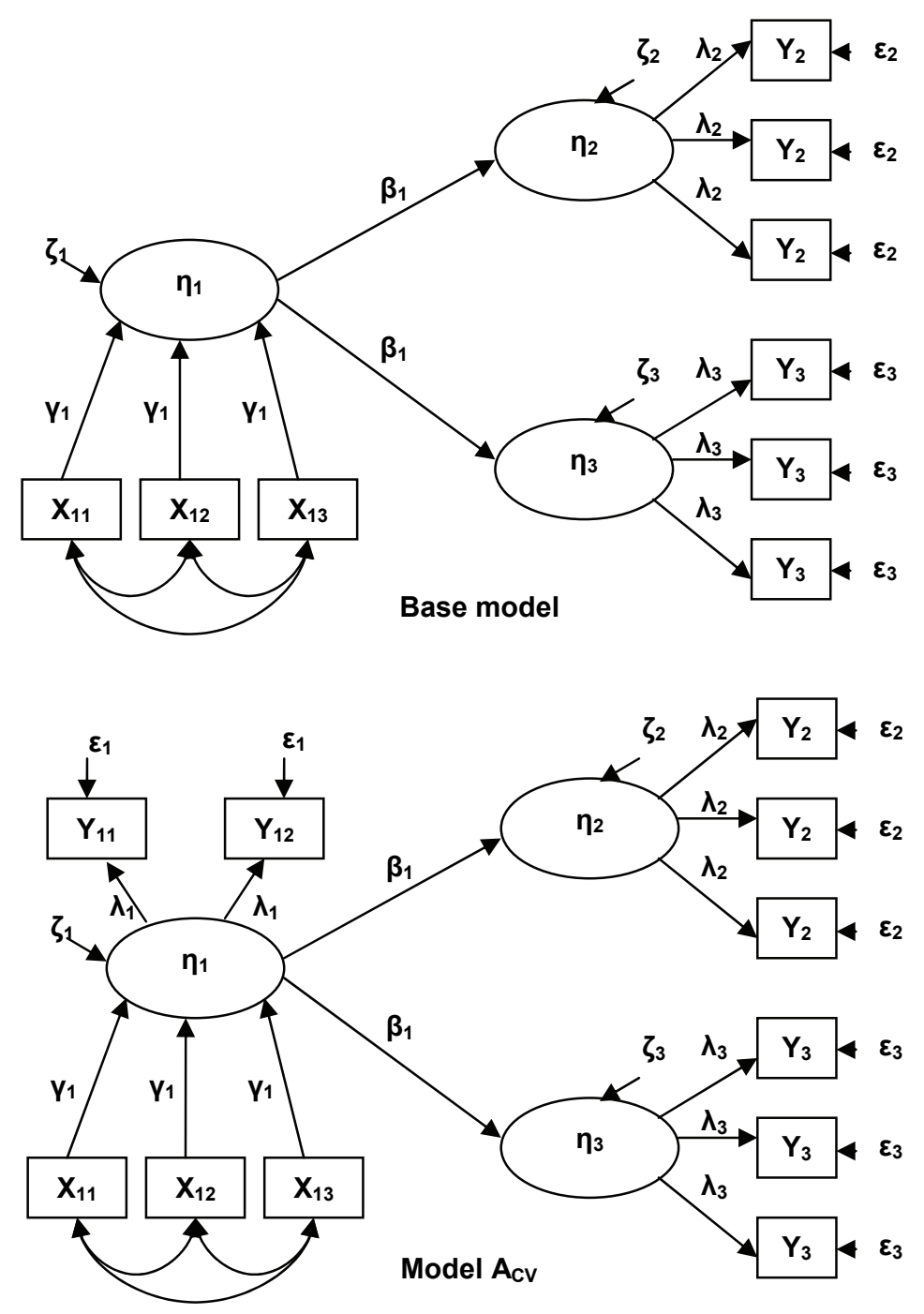

Figure 10 (part 1) - Specified models in covariance-based SEM software 
Fully Mediated Effects of Formative Measures Using MIMIC Constructs / Jiang et al.

formative latent variables if the MIMIC construct is unable to stabilize the measurement model.

\section{Process}

The population covariance matrix were calculated from the true parameters models shown in Figure 9, assuming a sample size of 250. We ran Monte Carlo simulations in EQS 6.1 using the population covariance matrix for each of the specific models in Figure 10 for both endogenous variable sets $\left(\eta_{2}\right.$ and $\eta_{3} ; \eta_{2}$ and $\eta_{4}$ ). This resulted in eight different models examined for the simulation. Consistent with Paxton et al. (2001), the analysis of the generated raw data sets, parameter estimations and fit statistics were estimated using 500 replications and only the converged samples and proper solutions were included in the analysis.

The first series of models (Figure 9A) consisted of one formatively-measured construct $\left(\eta_{1}\right)$ with two reflective endogenous constructs $\left(\eta_{2}\right.$ and $\left.\eta_{3}\right)$, where the structural estimation of $\eta_{1}$ on $\eta_{2}$ was 0.5 , and the structural estimation of $\eta_{1}$ on $\eta_{3}$ was 0.8 . In the second series (Figure 9B), we used different sets of endogenous constructs. The identical $\eta_{2}$ was
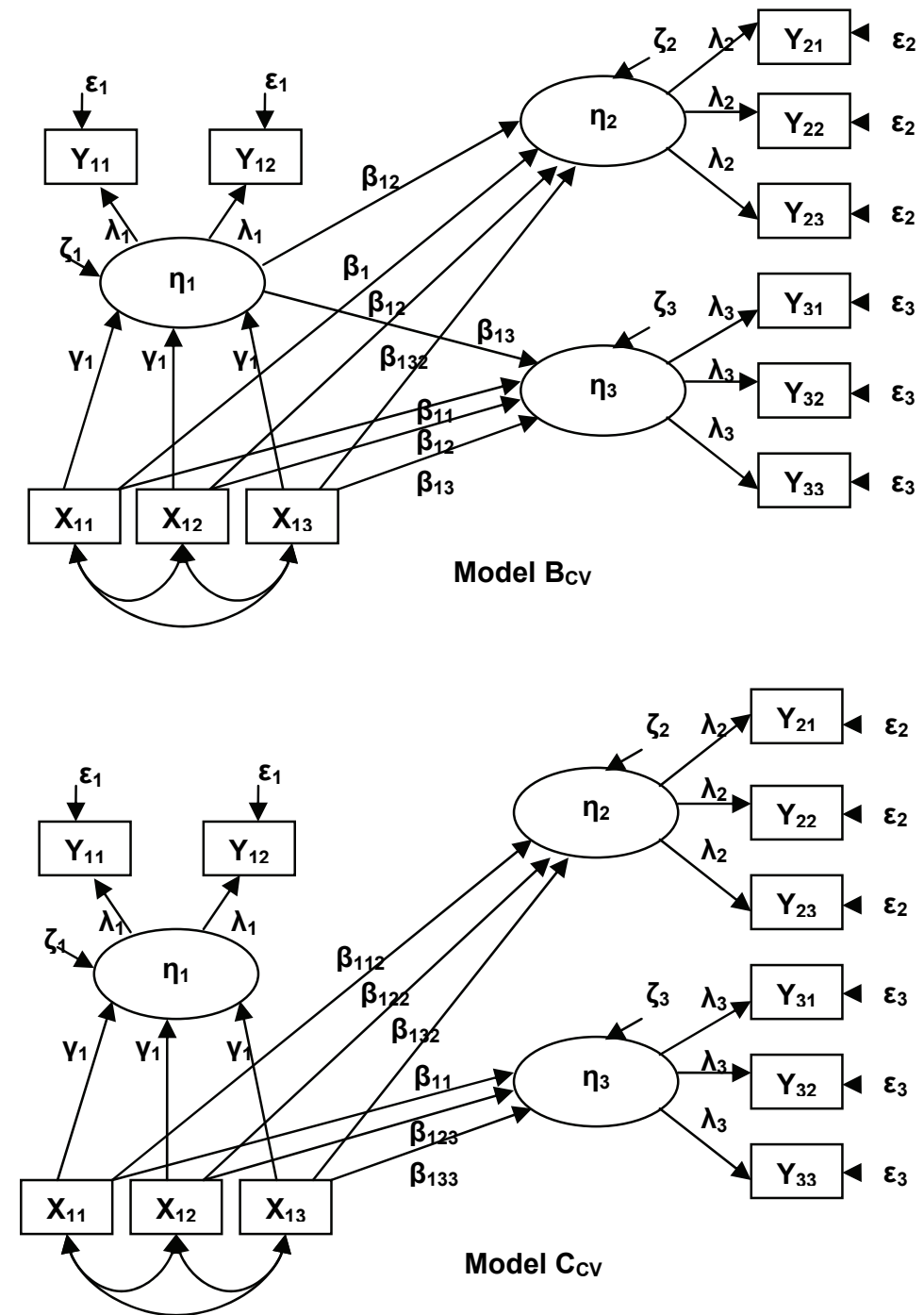

Figure 10 (part 2) - Specified models in covariance-based SEM software 
Fully Mediated Effects of Formative Measures Using MIMIC Constructs / Jiang et al.

still required to serve as an endogenous construct, and we replaced $\eta_{3}$ by $\eta_{4}$ as another endogenous construct. The second series of models consisted of one formative MIMIC model $\left(\eta_{1}\right)$ with two reflective endogenous constructs $\left(\eta_{2}\right.$ and $\left.\eta_{4}\right)$, where the structural estimation of $\eta_{1}$ on $\eta_{2}$ was 0.5 and the structural estimation of $\eta_{1}$ on $\eta_{4}$ was 0.2 . Hence, each series was composed of one formative exogenous construct with two reflective endogenous constructs.

\section{Expectations}

If the MIMIC construct avoids issues of interpretational confounding, the paths from the formative measures to the latent formative variable should not change nor should the direct path from $\eta_{1}$ to $\eta_{2}$ by replacing $\eta_{3}$ with $\eta_{4}$ Variation in the estimates when an endogenous variable changes would suggest that interpretational confounding is not mitigated when a MIMIC model is used. Further, we expect the MIMIC construct to act as a point variable and fully mediate the measures to the endogenous variables, indicating proportional structural effects and external consistency.

The examination of the relationships from the formative measures of the MIMIC construct to the endogenous constructs allowed us to examine whether the indirect effects and the direct effects are the same. We can calculate and compare the indirect effect of one formative measure in Model $A_{C V}$ and the direct effect of the same formative measure in Model $\mathrm{C}_{\mathrm{CV}}$. For example, to observe the mediating effect of the formative MIMIC construct in Model $A_{C V}$ and Model $C_{C V}$, the indirect effect of $X_{11}$ is the product of $\gamma_{11}{ }^{*} \beta_{12}$ and $\gamma_{11}{ }^{*} \beta_{13}$. These should be nearly equivalent to $\beta_{112}$ and $\beta_{113}$ if formative MIMIC model is a full mediator. Likewise, the direct paths to from the formative measures to the endogenous variables should be zero if the formative variable fully mediates the formative measures. This indirect effect and zero coefficients represent the meditating effect of formative MIMIC model on the relationship between its formative measures and endogenous constructs (Hair et al., 2010).

\section{Results}

Tables $1 \mathrm{a}$ and $1 \mathrm{~b}$ present the results of all eight models. The columns represent the different models, varying across the structure (Base Model in Table 1a, Models $A_{c V}, B_{C V}$ and $\mathrm{C}_{\mathrm{CV}}$ in Table $1 \mathrm{~b}$ ) as well as the endogenous variable sets $\left(\eta_{2}\right.$ and $\eta_{3}, \eta_{2}$ and $\left.\eta_{4}\right)$. The standard weights of the formative measures in the MIMIC construct are the first three rows of data. These should not vary or interpretational confounding is present the structural model. Further, if the path coefficient from $\eta_{1}$ to $\eta_{2}\left(\beta_{12}\right)$ varies when the model alters from $\eta_{3}$ to $\eta_{4}$, this would indicate a problem of interpretational confounding. As can be seen in Table $1 \mathrm{a}$, the formative measure weights and structural path coefficients in the base model (using formative measures only) vary, while the formative measure weights and structural path coefficients in Table $1 \mathrm{~b}$ do not vary to any degree across the rows when using a MIMIC construct for formative measurement. Interpretational confounding does not appear to be a problem when using a MIMIC construct with both formative and reflective measures, particularly when the reflective measures capture the construct well.

Considerations of the point variable property for external consistency considerations are evident in both Table 1 and Table 2. First, Table $1 \mathrm{~b}$ shows that the direct paths from the formative measures to the endogenous variables are not statistically different form zero (indeed close to zero) in model $\mathrm{B}_{\mathrm{Cv}}$. Further, Table 2 shows the computed values of the indirect path to $\eta_{2}$ in model $A_{C V}$ to allow comparison to the direct path to $\eta_{2}$ in model $C_{C v}$. The direct path values and the indirect values should be the same if there are no proportional violations. Direct path values are those determined as the path coefficients in model $\mathrm{C}_{\mathrm{CV}}$. Indirect values are the product of the path from the measure to the latent exogenous variable and the path from the exogenous to endogenous variable (the product is shown in the third column of table 2). The changes from the direct effects to the indirect effects are very low ( $t=0.473$, nonsignificant), indicating that the MIMIC formatively-measured construct mediates the 
Fully Mediated Effects of Formative Measures Using MIMIC Constructs / Jiang et al.

measures as desired providing a good point variable with desired external consistency for these models. Both tables lend optimism to showing formatively-measured constructs can be applied in the measurement model without leading to detriments in the structural model found by other researchers (Kim. et al, 2010).

\section{Table 1a - Model Estimation and Fit Indices for Base Model}

\begin{tabular}{|c|c|c|c|}
\hline Endogenous variables & $\eta_{2}, \eta_{3}$ & $\eta_{2}, \eta_{4}$ & Ave $\% \Delta$ \\
\hline \multicolumn{4}{|l|}{ Weights of formative measures } \\
\hline$x_{11} \rightarrow n_{1}\left(v_{11}\right)$ & 0.352 & 0.308 & -12.6 \\
\hline$x_{12} \rightarrow \eta_{1}\left(Y_{12}\right)$ & 0.448 & 0.383 & -14.5 \\
\hline $\mathrm{X}_{13} \rightarrow \eta_{1}\left(\mathrm{Y}_{13}\right)$ & 0.443 & 0.399 & -10.1 \\
\hline \multicolumn{4}{|l|}{ Standard path coefficients } \\
\hline$\eta 1 \rightarrow \eta 2(\beta 12)$ & 0.503 & 0.588 & 16.9 \\
\hline$X 11 \rightarrow \eta 2(\beta 112)$ & $\mathrm{N} / \mathrm{A}$ & $\mathrm{N} / \mathrm{A}$ & \\
\hline$X 12 \rightarrow \eta 2(\beta 122)$ & $\mathrm{N} / \mathrm{A}$ & $\mathrm{N} / \mathrm{A}$ & \\
\hline$X 13 \rightarrow \eta 2(\beta 132)$ & $\mathrm{N} / \mathrm{A}$ & $\mathrm{N} / \mathrm{A}$ & \\
\hline$\eta 1 \rightarrow \eta 3(\beta 13)$ & 0.805 & ----- & \\
\hline$X 11 \rightarrow \eta 3(\beta 113)$ & $\mathrm{N} / \mathrm{A}$ & ----- & \\
\hline$X 12 \rightarrow \eta 3(\beta 123)$ & $\mathrm{N} / \mathrm{A}$ & ----- & \\
\hline$X 13 \rightarrow \eta 3(\beta 133)$ & $\mathrm{N} / \mathrm{A}$ & ---- & \\
\hline$\eta 1 \rightarrow \eta 4(\beta 14)$ & ---- & 0.233 & \\
\hline$X 11 \rightarrow \eta 4(\beta 114)$ & ----- & $\mathrm{N} / \mathrm{A}$ & \\
\hline$X 12 \rightarrow \eta 4(\beta 124)$ & ----- & $\mathrm{N} / \mathrm{A}$ & \\
\hline$X 13 \rightarrow \eta 4(\beta 134)$ & ---- & $\mathrm{N} / \mathrm{A}$ & \\
\hline \multicolumn{4}{|l|}{ Fit Indices } \\
\hline Chi-sq(df) & $22.57(22)$ & $22.46(22)$ & \\
\hline GFI & 0.981 & 0.981 & \\
\hline CFI & 0.999 & 0.999 & \\
\hline $\mathrm{NFI}$ & 0.995 & 0.995 & \\
\hline RMSEA & 0.015 & 0.014 & \\
\hline
\end{tabular}

\section{Table 1b - Model Estimation and Fit Indices for Model Variations}


Fully Mediated Effects of Formative Measures Using MIMIC Constructs / Jiang et al.

\begin{tabular}{|c|c|c|c|c|c|c|c|c|c|}
\hline & \multicolumn{3}{|c|}{ Model $A_{c y}$} & \multicolumn{3}{|c|}{ Model $B_{c v}$} & \multicolumn{3}{|c|}{ Model $\mathrm{C}_{\mathrm{cv}}$} \\
\hline $\begin{array}{c}\text { Endogenous } \\
\text { variables }\end{array}$ & $\eta_{2}, \eta_{3}$ & $\eta_{2}, \eta_{4}$ & $\begin{array}{c}\text { Ave } \% \\
\Delta\end{array}$ & $\eta_{2}, \eta_{3}$ & $\mathbf{\eta}_{2}, \eta_{4}$ & $\begin{array}{c}\text { Ave } \% \\
\Delta\end{array}$ & $\eta_{2}, \eta_{3}$ & $\eta_{2}, \eta_{4}$ & $\begin{array}{c}\text { Ave } \% \\
\Delta\end{array}$ \\
\hline \multicolumn{10}{|c|}{ Weights of formative measures } \\
\hline$X_{11} \rightarrow \eta_{1}\left(\gamma_{11}\right)$ & 0.352 & 0.350 & -0.5 & 0.352 & 0.350 & -0.5 & 0.352 & 0.350 & -0.5 \\
\hline$X_{12} \rightarrow \eta_{1}\left(\gamma_{12}\right)$ & 0.459 & 0.452 & -1.6 & 0.450 & 0.452 & 0.4 & 0.450 & 0.452 & 0.4 \\
\hline$X_{13} \rightarrow \eta_{1}\left(\gamma_{13}\right)$ & 0.453 & 0.453 & -0.1 & 0.453 & 0.453 & 0.1 & 0.453 & 0.453 & -0.1 \\
\hline \multicolumn{10}{|c|}{ Standard path coefficients } \\
\hline$\eta_{1} \rightarrow \eta_{2}\left(\beta_{12}\right)$ & 0.498 & 0.498 & 0.1 & 0.490 & 0.493 & 0.5 & $\mathrm{~N} / \mathrm{A}$ & N/A & N/A \\
\hline $\mathrm{X}_{11} \rightarrow \eta_{2}\left(\beta_{112}\right)$ & $\mathrm{N} / \mathrm{A}$ & $\mathrm{N} / \mathrm{A}$ & & 0.005 & 0.002 & & 0.177 & 0.174 & \\
\hline $\mathrm{X}_{12} \rightarrow \eta_{2}\left(\beta_{122}\right)$ & $\mathrm{N} / \mathrm{A}$ & $\mathrm{N} / \mathrm{A}$ & & 0.004 & 0.001 & & 0.224 & 0.224 & \\
\hline $\mathrm{X}_{13} \rightarrow n_{2}\left(\beta_{132}\right)$ & $\mathrm{N} / \mathrm{A}$ & $\mathrm{N} / \mathrm{A}$ & & 0.003 & 0.006 & & 0.225 & 0.229 & \\
\hline$\eta_{1} \rightarrow \eta_{3}\left(\beta_{13}\right)$ & 0.799 & ---- & & 0.804 & ---- & & $\mathrm{N} / \mathrm{A}$ & ---- & \\
\hline $\mathrm{X}_{11} \rightarrow \mathrm{n}_{3}\left(\beta_{113}\right)$ & $\mathrm{N} / \mathrm{A}$ & ---- & & -0.001 & ---- & & 0.283 & ----- & \\
\hline$x_{12} \rightarrow n_{3}\left(\beta_{123}\right)$ & $\mathrm{N} / \mathrm{A}$ & ---- & & -0.005 & ----- & & 0.357 & ----- & \\
\hline$X_{13} \rightarrow n_{3}\left(\beta_{133}\right)$ & $\mathrm{N} / \mathrm{A}$ & ---- & & -0.002 & ---- & & 0.362 & ---- & \\
\hline$\eta_{1} \rightarrow \eta_{4}\left(\beta_{14}\right)$ & ---- & 0.194 & & ----- & 0.202 & & ---- & N/A & \\
\hline $\mathrm{X}_{11} \rightarrow \mathrm{n}_{4}\left(\beta_{114}\right)$ & ---- & N/A & & ---- & -0.007 & & ----- & 0.063 & \\
\hline$x_{12} \rightarrow n_{4}\left(\beta_{124}\right)$ & ---- & N/A & & ---- & -0.007 & & ---- & 0.086 & \\
\hline $\mathrm{X}_{13} \rightarrow \eta_{4}\left(\beta_{134}\right)$ & ---- & N/A & & ---- & 0.001 & & ---- & 0.093 & \\
\hline \multicolumn{10}{|l|}{ Fit Indices } \\
\hline $\begin{array}{l}\text { Chi-sq } \\
\text { (df) }\end{array}$ & $\begin{array}{c}40.14 \\
(39)\end{array}$ & $\begin{array}{c}40.41 \\
(39)\end{array}$ & & $\begin{array}{c}33.93 \\
(33)\end{array}$ & $\begin{array}{c}34.15 \\
(33)\end{array}$ & & $\begin{array}{c}104.35 \\
(35)\end{array}$ & $\begin{array}{c}49.06 \\
(35)\end{array}$ & \\
\hline GFI & 0.972 & 0.972 & & 0.976 & 0.976 & & 0.933 & 0.966 & \\
\hline $\mathrm{CFI}$ & 0.999 & 0.999 & & 0.999 & 0.999 & & 0.988 & 0.997 & \\
\hline $\mathrm{NFI}$ & 0.993 & 0.993 & & 0.994 & 0.994 & & 0.982 & 0.991 & \\
\hline RMSEA & 0.014 & 0.014 & & 0.014 & 0.015 & & 0.089 & 0.036 & \\
\hline \multicolumn{10}{|c|}{ Note: Bold items are significant at $p<0.05$} \\
\hline
\end{tabular}

\section{Table 2 - Computed effect of each formative measure on endogenous construct $\boldsymbol{\eta}_{\mathbf{2}}$}

\begin{tabular}{|l|c|c|c|c|c|c|c|}
\hline & \multicolumn{2}{|c|}{ Model $\mathrm{A}_{\mathrm{cv}}$} & $\begin{array}{c}\text { Indirect } \\
\text { effect }\end{array}$ & \multicolumn{2}{c|}{ Model $\mathrm{C}_{\mathrm{cv}}$} & Direct effect & $\% \Delta$ \\
\hline \multirow{2}{*}{$\begin{array}{l}\text { Endogenous } \\
\text { variables } \\
\left(\eta_{2}, \eta_{3}\right)\end{array}$} & $\mathrm{X}_{11} \rightarrow \eta_{2}$ & $\mathrm{~V}_{11}{ }^{*} \beta_{12}$ & 0.175 & $\mathrm{X}_{11} \rightarrow \eta_{2}$ & $\beta_{112}$ & 0.177 & 1.0 \\
\cline { 2 - 8 } & $\mathrm{X}_{12} \rightarrow \eta_{2}$ & $\mathrm{Y}_{12}{ }^{*} \beta_{12}$ & 0.229 & $\mathrm{X}_{12} \rightarrow \eta_{2}$ & $\beta_{122}$ & 0.224 & -2.1 \\
\cline { 2 - 8 } $\begin{array}{l}\text { Endogenous } \\
\text { variables } \\
\left(\eta_{2}, \eta_{4}\right)\end{array}$ & $\mathrm{X}_{13} \rightarrow \eta_{2}$ & $\mathrm{~V}_{13}{ }^{*} \beta_{12}$ & 0.225 & $\mathrm{X}_{13} \rightarrow \eta_{2}$ & $\beta_{132}$ & 0.225 & -0.4 \\
\cline { 2 - 8 } & $\mathrm{X}_{11} \rightarrow \eta_{2}$ & $\mathrm{~V}_{11}{ }^{*} \beta_{12}$ & 0.175 & $\mathrm{X}_{11} \rightarrow \eta_{2}$ & $\beta_{112}$ & 0.174 & -0.1 \\
\cline { 2 - 8 } & $\mathrm{X}_{12} \rightarrow \eta_{2}$ & $\mathrm{~V}_{12}{ }^{*} \beta_{12}$ & 0.225 & $\mathrm{X}_{12} \rightarrow \eta_{2}$ & $\beta_{122}$ & 0.224 & -0.5 \\
\hline
\end{tabular}


Fully Mediated Effects of Formative Measures Using MIMIC Constructs / Jiang et al.

\section{Illustrative Example: Web Site Service Quality}

We employ a simple model as an example (Figure 11) to demonstrate the issue of interpretational confounding and external consistency. The illustrative model is largely based on the work of Cenfetelli et al. (2008); we replicated a part of their research model and collected the data from 173 Yahoo online shopping center users. In our illustrative example, service quality consists of five latent variables, which is different from the work of Cenfetelli and Bassellier (2009) in which service quality is modeled with five indicators. This illustrative model includes eight constructs: a second-order exogenous formatively measured construct (service quality) with five first-order reflectively measured constructs (assurance, empathy, reliability, responsiveness and tangibles) and three endogenous reflectively measured constructs (perceived usefulness, satisfaction and perceived value). To satisfy the sample size requirements for SEM modeling and maintain a parsimonious illustrative model, this study estimated a simple, first-order, formativelymeasured. The five first-order reflectively measured constructs are converted into single measures using factor scores in order to convert service quality into a first-order formatively-measured construct.

Firstly, we assessed the validity of the measurement items within the reflective first-order constructs. Then, we used the factor score of each of the five first-order constructs to represent the formative indicators of secondorder service quality construct. In this analysis, we modeled service quality as a MIMIC model and included two reflective items, with items such as "Overall, Yahoo online shopping center provides a high level of service". This MIMIC construct was used to test the structural relationship among service quality and perceived usefulness, satisfaction and perceived value. Descriptive statistics, convergent validity and discriminant validity of all measurement items are reported in Appendix B.

Consistent with the Base Model, ModelAcv and ModelCcv (see Figure 10), we examined the relationships between service quality and both endogenous construct sets (satisfaction and perceived playfulness; satisfaction and perceived value). As demonstrated in Table 3, when comparing the results in the Base Model and Model Acv, the standard weights of formative measures in the MIMIC construct are more stable than that of non-MIMIC construct. This demonstrates that the threat of

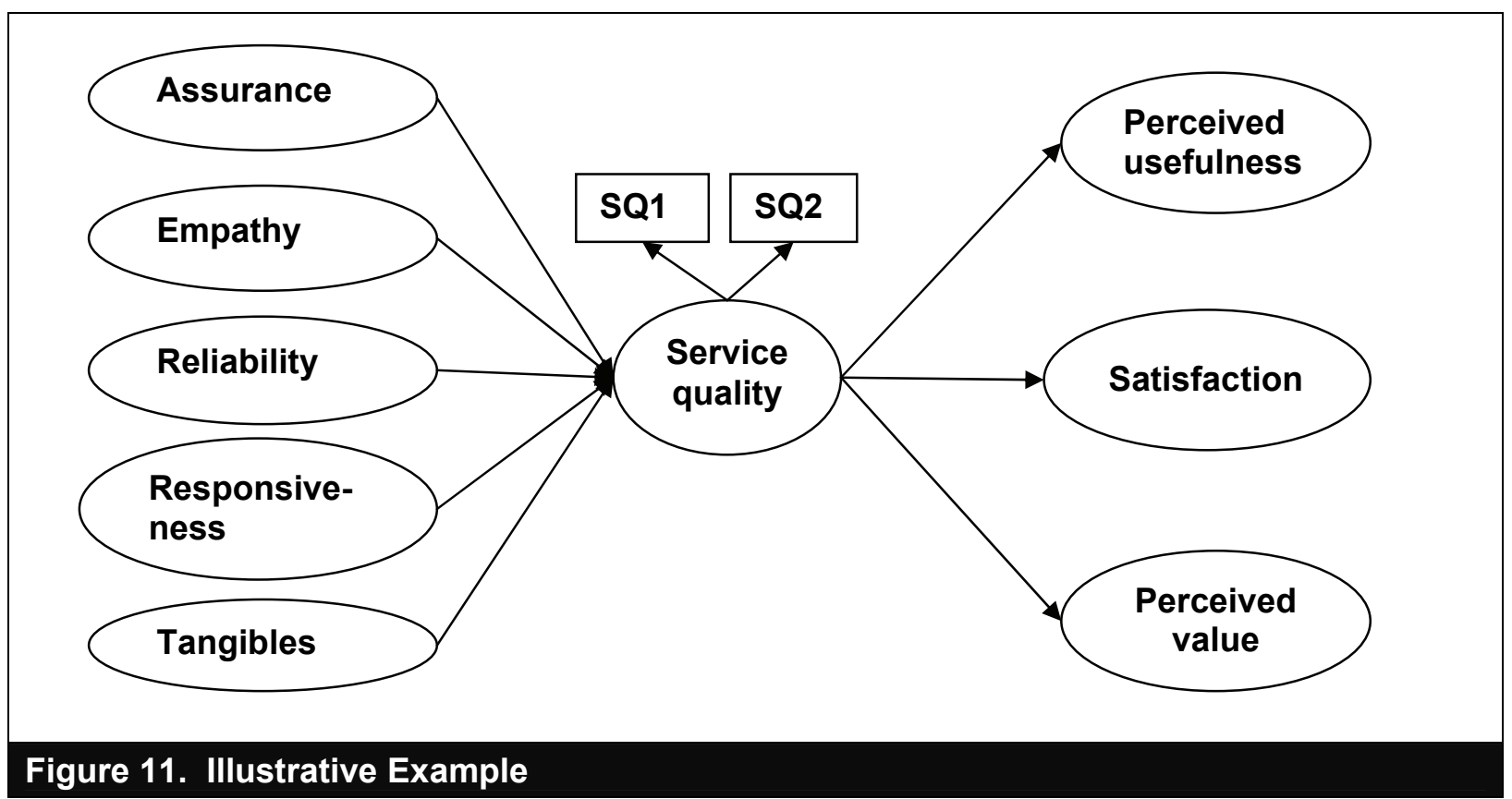


Fully Mediated Effects of Formative Measures Using MIMIC Constructs / Jiang et al.

interpretational confounding was reduced in this example when a MIMIC model was used to model the formatively-measured construct.

The direct path values and indirect path values of the five formative indicators on satisfaction are shown in Table 4. The changes from the direct effects to the indirect effects are higher than the simulation results. We conducted t-test to compare the indirect effect and direct effect. First, we computed the change between the indirect effect in Model Acv and direct effect in Model Ccv, and the results indicated that the change rate is insig- nificant $(\mathrm{t}=-0.92$ for endogenous variable set $1 ; t=-0.30$ for endogenous variable set 2 ). Second, we computed the change between the indirect effect in Model Acv and direct effect in Model Bcv, and the results indicated that the change rate is insignificant $(t=1.66$ for endogenous variable set $1 ; t=1.46$ for endogenous variable set 2 ). This suggests that the MIMIC service quality construct mediates the measures, and demonstrates the MIMIC construct provides a good point variable for external consistency.

\section{Table 3 - Model Estimation}

\begin{tabular}{|c|c|c|c|c|c|c|}
\hline & \multicolumn{3}{|c|}{ Base Model } & \multicolumn{3}{|c|}{ Model Acv } \\
\hline $\begin{array}{l}\text { Endogenous } \\
\text { variable }\end{array}$ & SAT, PU & SAT, PV & $\begin{array}{l}\text { Ave } \\
\% \Delta\end{array}$ & SAT, PU & SAT, PV & $\begin{array}{l}\text { Ave } \\
\% \Delta\end{array}$ \\
\hline \multicolumn{7}{|c|}{ Weights of formative measures } \\
\hline$A S S \rightarrow S Q$ & 0.06 & 0.10 & 67 & 0.09 & 0.10 & 11 \\
\hline $\mathrm{EMP} \rightarrow \mathrm{SQ}$ & 0.10 & 0.19 & 90 & 0.13 & 0.14 & 8 \\
\hline $\mathrm{REL} \rightarrow \mathrm{SQ}$ & 0.53 & 0.42 & -21 & 0.48 & 0.45 & -6 \\
\hline $\mathrm{RES} \rightarrow \mathrm{SQ}$ & 0.11 & 0.15 & 36 & 0.19 & 0.19 & 0 \\
\hline $\mathrm{TAN} \rightarrow \mathrm{SQ}$ & 0.02 & 0.10 & 400 & 0.10 & 0.11 & 10 \\
\hline \multicolumn{7}{|c|}{ Standard path coefficients } \\
\hline SQ $\rightarrow$ SAT & 0.93 & 0.85 & 8.6 & 0.80 & 0.79 & \\
\hline $\mathrm{SQ} \rightarrow \mathrm{PU}$ & 0.72 & & & 0.70 & & \\
\hline$S Q \rightarrow P V$ & & 0.66 & & & 0.66 & \\
\hline \multicolumn{7}{|l|}{ Fit Index } \\
\hline Chi-sq(df) & $68.63(42)$ & $75.841(42)$ & & $106.39(65)$ & $95.61(65)$ & \\
\hline GFI & 0.935 & 0.932 & & 0.919 & 0.927 & \\
\hline $\mathrm{CFI}$ & 0.982 & 0.975 & & 0.978 & 0.983 & \\
\hline $\mathrm{NFI}$ & 0.955 & 0.946 & & 0.947 & 0.949 & \\
\hline RMSEA & 0.064 & 0.072 & & 0.064 & 0.055 & \\
\hline \multicolumn{7}{|c|}{$\begin{array}{l}\text { Notes: } \\
\text { Bold items are significant at } p<0.05 \\
\text { SQ = Service quality } \\
\text { SAT = Satisfaction } \\
\text { PU = Perceived playfulness } \\
\text { PV = Perceived value }\end{array}$} \\
\hline
\end{tabular}




\begin{tabular}{|c|c|c|c|c|c|c|c|c|}
\hline & & $\begin{array}{c}\text { Model } A_{c v} \\
\text { Indirect } \\
\text { effect }\end{array}$ & $\begin{array}{c}\text { Model } \mathrm{C}_{\mathrm{cv}} \\
\text { Direct effect }\end{array}$ & $\% \Delta$ & $\begin{array}{c}\text { t- } \\
\text { value }\end{array}$ & $\begin{array}{c}\text { Model } \mathrm{B}_{\mathrm{CV}} \\
\text { Direct effect }\end{array}$ & $\% \Delta$ & $\begin{array}{c}\text { t- } \\
\text { value }\end{array}$ \\
\hline \multirow{5}{*}{$\begin{array}{c}\text { SET } 1 \\
\text { Endogenous } \\
\text { variables } \\
\text { (SAT, PU) }\end{array}$} & ASS $\rightarrow$ SAT & 0.07 & 0.09 & 29 & \multirow{5}{*}{-0.92} & 0.05 & 29 & \multirow{5}{*}{1.66} \\
\hline & $\mathrm{EMP} \rightarrow \mathrm{SAT}$ & 0.09 & 0.14 & 56 & & 0.05 & 44 & \\
\hline & $\mathrm{REL} \rightarrow \mathrm{SAT}$ & 0.34 & 0.46 & 35 & & 0.12 & 65 & \\
\hline & RES $\rightarrow$ SAT & 0.13 & 0.11 & -15 & & 0.02 & -85 & \\
\hline & TAN $\rightarrow$ SAT & 0.07 & 0.03 & -57 & & 0.10 & 43 & \\
\hline \multirow{5}{*}{$\begin{array}{c}\text { SET } 2 \\
\text { Endogenous } \\
\text { variables } \\
\text { (SAT, PV) }\end{array}$} & ASS $\rightarrow$ SAT & 0.08 & 0.09 & 12 & \multirow{5}{*}{-0.30} & 0.05 & -38 & \multirow{5}{*}{1.46} \\
\hline & $\mathrm{EMP} \rightarrow \mathrm{SAT}$ & 0.12 & 0.14 & 17 & & 0.05 & -58 & \\
\hline & $\mathrm{REL} \rightarrow \mathrm{SAT}$ & 0.36 & 0.46 & 28 & & 0.12 & -67 & \\
\hline & $\mathrm{RES} \rightarrow \mathrm{SAT}$ & 0.15 & 0.11 & -27 & & 0.02 & -87 & \\
\hline & TAN $\rightarrow$ SAT & 0.08 & 0.03 & -63 & & 0.10 & 25 & \\
\hline \multicolumn{9}{|c|}{$\begin{array}{l}\text { Notes: } \\
\text { ASS = Assurance } \\
\text { RES = Responsiveness } \\
\text { PU = Perceived playfulness }\end{array}$} \\
\hline
\end{tabular}

\section{Conclusions}

Concerns for formatively-measured constructs include issues of interpretational confounding and external consistency. Prior work establishes that these problems exist in correctly specified measurement models and not just misspecified models. A MIMIC measurement construct, with two reflective measures in addition to formative measures, might resolve these issues. The contribution of this study is to establish through simulation that the MIMIC construct serves as a point variable in a structural equation model such that interpretational confounding is avoided and external consistency is established by properties of full mediation of the measures by the construct on the endogenous variables. Formative measures can be applied in research if the measurement model is properly built to include two reflective items in a MIMIC measurement model for each formativelymeasured construct.

The burden on researchers is not light when using formatively-measured constructs. The choice of using either a formatively-measured construct or a reflectively measured construct must be theoretically justified. However, au- tomatically selecting a reflectively-measured construct when formative measurement would be more appropriate can negatively impact the understanding of the phenomenon of interest given that reflective and formative measures can provide different insights about a construct and lead to misspecification errors and estimation bias. Once the formatively-measured construct is selected, the researcher must demonstrate that all formative dimensions are included, interpretational confounding is mitigated and external consistency is present. The use of a MIMIC model with two reflective measures should be strongly considered in order to address scaling problems in an SEM. This was demonstrated even in cases where the formative measures are significant, complete, and free of multicollinearity - in other words even a well measured formative construct is subject to problems that can be enhanced by employing a MIMIC construct in the model. The reflective measures should be rigorously evaluated as appropriate for a measurement model.

From the reviewer perspective, when research employs a formatively-measured construct there must also be assurance that the known problems of interpretational confound- 
Fully Mediated Effects of Formative Measures Using MIMIC Constructs / Jiang et al.

ing and external consistency are somehow alleviated. Addressing the issue of proportionality is crucial in attaining external consistency and reducing interpretational confounding. Application of the MIMIC model may not be a solution unless the reflective measures exhibit measurement properties traditionally expected on rigorous research. Further, just because a researcher has two reflective items, it does not suggest that the construct should be measured reflectively as opposed to both reflectively and formatively. While the introduction of one more reflective item would fully identify the reflectivelymeasured construct, the researcher may want to use formative measures to understand specific contributing factors or examine theoretical concepts related to the construct empirically.

Several limitations to this study should be considered. First, only exogenous variables are considered. The use of formative measures in a construct has differing implications in an SEM depending on placement within a model, thus, consideration of strictly exogenous variables in this paper is appropriate. Further studies of formativelymeasured endogenous constructs are essential to understand their unique implications.

\section{References}

Aguirre-Urreta, M. I., and Marakas G. M. (2012) "Revisiting Bias Due to Construct Misspecification: Different Result from Considering Coefficients in Standardized Form," MIS Quarterly, 36(1), pp. 123-138.

Anderson, C. L., and Agarwal, R. (2010) "Practicing Safe Computing: A Multimethod Empirical Examination of Home Computer User Security Behavioral Intentions," MIS Quarterly, 34(3), pp. 613-643.

Anderson, J. C., and Gerbing, D. W. (1982) "Some Methods for Respecifying Measurement Models to Obtain Unidimensional Construct Measurement," Journal of Marketing Research, 19(4), pp. 453-460.
Endogenous, formatively-measured constructs at the path's end must accommodate the theoretical considerations of the upstream variables without violating the precept that the formative indicators completely specify the variable. The inclusion of a direct relationship leading into the formatively-measured construct adds an additional formative factor, thus, nullifying the original formativelymeasured construct as valid under original measurement assumptions. Therefore, the MIMIC approach might be applied to the endogenous variables, but studies should still be conducted. Secondly, the simulation assumes the reflective measures in the MIMIC construct to have effectively no error, restricting conclusions to MIMIC constructs where the reflective items are especially representative. The degree of quality in the reflective measures and the reflective endogenous variables is a question that must be addressed in further work. Lastly, we examine MIMIC models that develop reflective measures for the construct that is consistent with the theoretical definition of the construct, while other proposed MIMIC models consider additional downstream variables. The efficacy of this alternate approach requires examination as well.

Bagozzi, R. P. (2011) "Measurement and Meaning in Information Systems and Organizational Research: Methodological and Philosophical Foundations," MIS Quarterly, 35(2), pp. 261292.

Blalock, H. (1969). Theory Construction, from Verbal to Mathematical Formulations. Englewood Cliffs, NJ: Prentice Hall.

Blalock, H. M. (1964). Causal Inferences in Nonexperimental Research. University of North Carolina Press, Chapel Hill, $\mathrm{NC}$.

Bollen, K. A. (2011) "Evaluating Effect, Composite, and Causal Indicators in Structural Equation Models," MIS Quarterly, 35(2), pp. 359-372. 
Bollen, K., and Lennox, R. (1991) "Conventional Wisdom on Measurement: A Structural Equation Perspective," Psychological Bulletin, 110(2), pp. 305-314.

Bollen, K. A. (1989). Structural Equations with Latent Variables. New York: John Wiley \& Sons.

Bollen, K. A. (2007) "Interpretational Confounding Is Due to Misspecification, Not to Type of Indicator: Comment on Howell, Breivik, and Wilcox (2007)," Psychological methods, 12(2), pp. 219-228.

Bollen, K.A., and Davis, W.R. (1994) "Causal Indicator Models: Identification, Estimation, and Testing," Working paper, University of North Carolina at Chapel Hill.

Borsboom, D., Mellenbergh, G. J., and Van Heerden, J. (2003) "The Theoretical Status of Latent Variables," Psychological Review, 110(2), pp. 203-218.

Burt, R. S. (1976) "Interpretational Confounding of Unobserved Variables in Structural Equation Models," Sociological methods \& research, 5(1), pp. 3-52.

Burton-Jones, A. (2009) "Minimizing Method Bias through Programmatic Research," MIS Quarterly, 33(3), pp. 445-471.

Cenfetelli, R. T., and Bassellier, G. (2009) "Interpretation of Formative Measurement in Information Systems Research," MIS Quarterly, 33(4), pp. 689-707.

Cenfetelli, R. T., Benbasat, I., and AlNatourand S. (2008) " Addressing the What and How of Online Services: Positioning Supporting-Services Functionality and Service Quality for Business-to-Consumer Success," Information Systems Research, 19(2), pp. 161-181.

Chen, D. Q., Preston, D. S., and Xia, W. (2010) "Antecedents and Effects of
CIO Supply-Side and Demand-Side Leadership: A Staged Maturity Model," Journal of Management Information Systems, 27(1), pp. 231-271.

Chengalur-Smith, I., Sidorova, A., and Daniel, S. L. (2010) "Sustainability of Free/Libre Open Source Projects: A Longitudinal Study," Journal of the Association for Information Systems, 11(11/12), pp. 657-683.

Choi, S. Y., Lee, H., and Yoo, Y. (2010) "The Impact of Information Technology and Transactive Memory Systems on Knowledge Sharing, Application, and Team Performance: A Field Study," MIS Quarterly, 34(4), pp. 855-870.

Coltman, T., Devinney, T. M., Midgley, D. F., and Venaik, S. (2008) "Formative Versus Reflective Measurement Models: Two Applications of Formative Measurement," Journal of Business Research, 61(12), pp. 1250-1262.

D'Arcy, J., Hovav, A., and Galletta, D. (2009) "User Awareness of Security Countermeasures and Its Impact on Information Systems Misuse: A Deterrence Approach," Information Systems Research, 20(1), pp. 79-98.

Datta, P. (2011) "A Preliminary Study of Ecommerce Adoption in Developing Countries," Information Systems Journal, 21(1), pp. 3-32.

Davis, F. D. (1989) "Perceived Usefulness, Perceived Ease of Use, and User Acceptance of Information Technology," MIS Quarterly, 13(3), pp. 319-340.

Davis, J. M., Kettinger, W. J., and Kunev, D. G. (2009) "When Users Are IT Experts Too: The Effects of Joint It Competence and Partnership on Satisfaction with Enterprise-Level Systems Implementation," European Journal of Information Systems, 18(1), pp. 26-37.

Diamantopoulos, A. (1999) "Export Performance Measurement: Reflective Versus Formative Indicators," Interna- 
Fully Mediated Effects of Formative Measures Using MIMIC Constructs / Jiang et al.

tional Marketing Review, 16(6), pp. 444-457.

Diamantopoulos, A. (2006) "The Error Term in Formative Measurement Models: Interpretation and Modeling Implications," Journal of Modeling in Management, 1(1), pp. 7-17.

Diamantopoulos, A. (2011) "Incorporating Formative Measures into CovarianceBased Structural Equation Models," MIS Quarterly, 33(4), pp. 335-358.

Diamantopoulos, A., Riefler, P., and Roth, K. P. (2008) "Advancing Formative Measurement Models," Journal of Business Research, 61(12), pp. 12031218.

Diamantopoulos, A., and Winklhofer, H. M. (2001) "Index Construction with Formative Indicators: An Alternative to Scale Development," Journal of Marketing Research, 38(2), pp. 269-277.

Edwards, J. R., and Bagozzi, R. P. (2000) "On the Nature and Direction of Relationships between Constructs and Measures," Psychological Methods, 5(2), pp. 155-174.

Fornell, C., and Bookstein, F. L. (1982) "Two Structural Equation Models: LISREL and PLS Applied to Consumer ExitVoice Theory," Journal of Marketing research, 19(4), pp. 440-452.

Franke, G. R., Preacher, K. J., and Rigdon, E. E. (2008) "Proportional Structural Effects of Formative Indicators," Journal of Business Research, 61(12), pp. 1229-1237.

Goo, J., Kishore, R., Rao, H. R., and Nam, K. (2009) "The Role of Service Level Agreements in Relational Management of Information Technology Outsourcing: An Empirical Study," MIS Quarterly, 33(1), pp. 119-145.

Gopal, A., and Gosain, S. (2011) "The Role of Organizational Controls and Boundary Spanning in Software Development Outsourcing: Implications for Project Performance," Information Systems Research, 21(4), pp. 960982.

Hair, J. F., Black, W.C., Babin, B.J., Anderson, R.E. (2010). Multivariate Data Analysis (7th ed). Englewood Cliffs, New Jersey: Pearson Prentice Hall.

Hardin, A., Chang, J., and Fuller, M. (2008a) "Clarifying the Use of Formative Measurement in the IS Discipline," Journal of the Association for Information Systems, 9, pp. 545-547.

Hardin, A., Chang, J., and Fuller, M. (2008b) "Formative versus Reflective Measurement: Comment on Marakas, Johnson, and Clay (2007)," Journal of the Association for Information Systems, 9, pp. 519-535.

Hayduk, L. A. (1987). Structural Equation Modeling with LISREL: Essentials and Advances. Baltimore, MD: Johns Hopkins Univ Pr.

Herath, T., and Rao, H. R. (2009) "Protection Motivation and Deterrence: A Framework for Security Policy Compliance in Organisations," European Journal of Information Systems, 18(2), pp. 106125.

Howell, R. D., Breivik, E., and Wilcox, J. B. (2007) "Reconsidering Formative Measurement," Psychological Methods, 12(2), pp. 205-218.

Hsieh, J. J., Rai, A., and Keil, M. (2011) "Addressing Digital Inequality for the Socioeconomically Disadvantaged through Government Initiatives: Forms of Capital That Affect Ict Utilization," Information Systems Research, 22(2), pp. 233-253.

lacovou, C. L., Thompson, R. L., and Smith, H. J. (2009) "Selective Status Reporting in Information Systems Projects: A Dyadic-Level Investigation," MIS Quarterly, 33(4), pp. 785-810.

Jarvis, C. B., MacKenzie, S. B., and Podsakoff, P. M. (2003) "A Critical Review 
Fully Mediated Effects of Formative Measures Using MIMIC Constructs / Jiang et al.

of Construct Indicators and Measurement Model Misspecification in Marketing and Consumer Research," Journal of Consumer Research, 30(2), pp. 199-218.

Johnston, A. C., and Warkentin, M. (2010) "Fear Appeals and Information Security Behaviors: An Empirical Study," MIS Quarterly, 34(3), pp. 549-566.

Ke, W., and Zhang, P. (2010) "The Effects of Extrinsic Motivations and Satisfaction in Open Source Software Development," Journal of the Association for Information Systems, 11(12), pp. 784808.

Kim, D., and Benbasat, I. (2009) "TrustAssuring Arguments in B2C ECommerce: Impact of Content, Source, and Price on Trust," Journal of Management Information Systems, 26(3), pp. 175-206.

Kim, D. J., Ferrin, D. L., and Rao, H. R. (2009) "Trust and Satisfaction, Two Stepping Stones for Successful E-Commerce Relationships: A Longitudinal Exploration," Information Systems Research, 20(2), pp. 237-257.

Kim, G., Shin, B., and Grover, V. (2010) "Investigating Two Contradictory Views of Formative Measurement in Information Systems Research," MIS Quarterly, 34(2), pp. 345-365.

Klein, R., and Rai, A. (2009) "Interfirm Strategic Information Flows in Logistics Supply Chain Relationships," MIS Quarterly, 33(4), pp. 735-762.

Lee, G., and Xia, W. (2010) "Toward Agile: An Integrated Analysis of Quantitative and Qualitative Field Data," MIS Quarterly, 34(1), pp. 87-107.

Lee, Y., and Larsen, K. R. (2009) "Threat or Coping Appraisal: Determinants of SMB Executives' Decision to Adopt Anti-Malware Software," European Journal of Information Systems, 18(2), pp. 177-187.
Liang, H., Xue, Y., Ke, W., and Wei, K. K. (2010) "Understanding the Influence of Team Climate on IT Use," Journal of the Association for Information Systems, 11(8), pp. 414-432.

Lowry, P. B., Cao, J., and Everard, A. (2011) "Privacy Concerns Versus Desire for Interpersonal Awareness in Driving the Use of Self-Disclosure Technologies: The Case of Instant Messaging in Two Cultures," Journal of Management Information Systems, 27(4), pp. 163-200.

Lowry, P. B., Romano Jr, N. C., Jenkins, J. L., and Guthrie, R. W. (2009) "The CMC Interactivity Model: How Interactivity Enhances Communication Quality and Process Satisfaction in Lean-Media Groups," Journal of Management Information Systems, 26(1), pp. 155195.

MacCallum, R. C., and Browne, M. W. (1993) "The Use of Causal Indicators in Covariance Structure Models: Some Practical Issues," Psychological Bulletin, 114, pp. 533-533.

MacKenzie, S. B., Podsakoff, P. M., and Jarvis, C. B. (2005) "The Problem of Measurement Model Misspecification in Behavioral and Organizational Research and Some Recommended Solutions," Journal of Applied Psychology, 90(4), pp. 710-730.

MacKenzie, S. B., Podsakoff, P. M., and Podsakoff, N. P. (2011) "Construct Measurement and Validation Procedures In MIS and Behavioral Research: Integrating New and Existing Techniques," MIS Quarterly, 35(2), pp. 293-334.

Meso, P., Musa, P., Straub, D., and Mbarika, V. (2009) "Information Infrastructure, Governance, and Socio-Economic Development in Developing Countries," European Journal of Information Systems, 18(1), pp. 52-65. 
Fully Mediated Effects of Formative Measures Using MIMIC Constructs / Jiang et al.

Pavlou, P. A., and El Sawy, O. A. (2010) "The "Third Hand": IT-Enabled Competitive Advantage in Turbulence through Improvisational Capabilities," Information Systems Research, 21(3), pp. 443471.

Paxton, P., Curran, P. J., Bollen, K. A., Kirby, J., and Chen, F. (2001) "Monte Carlo Experiments: Design and Implementation," Structural Equation Modeling, 8(2), pp. 287-312.

Pee, L. G., Kankanhalli, A., and Kim, H. W. (2010) "Examining Knowledge Sharing in Is Development Projects: A Social Interdependence Perspective," Journal of the Association for Information Systems 11(10), pp. 550-575.

Petter, S., Straub, D., and Rai, A. (2007) "Specifying Formative Constructs in Information Systems Research," MIS Quarterly, 31(4), pp. 623-656.

Phang, C. W., Atrevi, K., and Rajiv, S. (2009) "Usability and Sociability in Online Communities: A Comparative Study of Knowledge Seeking and Contribution," Journal of the Association for Information Systems, 10(10), pp. 721747.

Posey, C., Lowry, P. B., Roberts, T. L., and Ellis, T. S. (2010) "Proposing the Online Community Self-Disclosure Model: The Case of Working Professionals in France and the UK Who Use Online Communities," European Journal of Information Systems, 19(2), pp. 181-195.

Preston, D. S., and Karahanna, E. (2009) "Antecedents of IS Strategic Alignment: A Nomological Network," Information Systems Research, 20(2), pp. 159-179.

Rai, A., Brown, P., and Tang, X. (2009) "Organizational Assimilation of Electronic Procurement Innovations," Journal of Management Information Systems, 26(1), pp. 257-296.
Rai, A., and Tang, X. (2010) "Leveraging IT Capabilities and Competitive Process Capabilities for the Management of Interorganizational Relationship Portfolios," Information Systems Research, 21(3), pp. 516-542.

Sia, C. L., Lim, K. H., Leung, K., Lee, M., Huang, W. W., and Benbasat, I. (2009) "Web Strategies to Promote Internet Shopping: Is Cultural-Customization Needed?" MIS Quarterly, 33(3), pp. 491-512.

Sila, I. (2010) "Do Organisational and Environmental Factors Moderate the Effects of Internet-Based Interorganisational Systems on Firm Performance?" European Journal of Information Systems, 19(5), pp. 581-600.

Shin, B., and Kim, G. (2011) "Investigating the Reliability of Second-Order Formative Measurement in Information Systems Research," European Journal of Information Systems, 20(5), pp. 608-623.

Siponen, M., and Vance, A. (2010) "Neutralization: New Insights into the Problem of Employee Information Systems Security Policy Violations," MIS Quarterly, 34(3), pp. 487-502.

Spears, J. L., and Barki, H. (2010) "User Participation in Information Systems Security Risk Management," MIS Quarterly, 34(3), pp. 503-522.

Titah, R., and Barki, H. (2009) "Nonlinearities between Attitude and Subjective Norms in Information Technology Acceptance: A Negative Synergy?" MIS Quarterly, 33(4), pp. 827-844.

Tiwana, A., and Konsynski, B. (2010) "Complementarities between Organizational It Architecture and Governance Structure," Information Systems Research, 21(2), pp. 288-304.

Treiblmaier, H., Bentler, P.M., and Mair P. (2011) "Formative Constructs Implemented via Common Factors," Struc- 
Fully Mediated Effects of Formative Measures Using MIMIC Constructs / Jiang et al.

tural Equation Modeling: A Multidisciplinary Journal, 18(1), pp. 1-17

Venkatesh, V., Zhang, X., and Sykes, T. A. (2011) "Dotors Do Too Little Technology: A Longitudinal Field Study of an Electronic Healthcare System Implementation," Information Systems Research, 22(3), pp. 523-546.

Wang, Y., and Haggerty, N. (2011) "Individual Virtual Competence and Its Influence on Work Outcomes," Journal of Management Information Systems, 27(4), pp. 299-334.

Warkentin, M., Johnston, A. C., and Shropshire, J. (2011) "The Influence of the Informal Social Learning Environment on Information Privacy Policy Compliance Efficacy and Intention," European Journal of Information Systems, 20(3), pp. 267-284.

Wells, J. D., Parboteeah, V., and Valacich, J. S. (2011) "Online Impulse Buying: Understanding the Interplay between Consumer Impulsiveness and Website Quality," Journal of the Association for Information Systems, 12(1), pp. 32-56.

Wells, J. D., Valacich, J. S., and Hess, T. J. (2011) "What Signal Are You Sending? How Website Quality Influences Perceptions of Product Quality and Purchase Intentions," MIS Quarterly, 35(2), pp. 373-396.
Whitaker, J., Mithas, S., and Krishnan, M. S. (2010) "Organizational Learning and Capabilities for Onshore and Offshore Business Process Outsourcing," Journal of Management Information Systems, 27(3), pp. 11-42.

Wilcox, J. B., Howell, R. D., and Breivik, E. (2008) "Questions About Formative Measurement," Journal of Business Research, 61(12), pp. 1219-1228.

Winklhofer, H. M., and Diamantopoulos, A. (2002) "Managerial Evaluation of Sales Forecasting Effectiveness: A MIMIC Modeling Approach," International Journal of Research in Marketing, 19(2), pp. 151-166.

Xue, Y., Liang, H., and Wu, L. (2011) "Punishment, Justice, and Compliance in Mandatory It Settings," Information Systems Research, 22(2), pp. 400414.

Yang, Y., Stafford, T. F., and Gillenson, M. (2011) "Satisfaction with Employee Relationship Management Systems: The Impact of Usefulness on Systems Quality Perceptions," European Journal of Information Systems, 20(2), pp. 221-236.

Zhao, K., Xia, M., and Shaw, M. J. (2011) "What Motivates Firms to Contribute to Consortium-Based E-Business Standardization?," Journal of Management Information Systems, 28(2), pp. 305-334. 
Fully Mediated Effects of Formative Measures Using MIMIC Constructs / Jiang et al.

\begin{abstract}
About the Authors
James Jiang is the Distinguished Professor of Information Systems, School of Accounting and Business Information Systems, the Australian National University, Australia. Currently, he is also the honorary Distinguished Chair Professor of Management, National Taiwan University, Taiwan. Professor Jiang's current research interests are IS Project and Program Management. He has published over 150 academic journal articles on these and other areas, which have been cited over 3000 times. He has been ranked by articles appeared in the Communication of Associations of Information Systems and European Journal of Information Systems as one of the most productive IS researchers globally. Currently, he serves as on the editorial boards of the International Journal of IT Project Management and Information \& Management (I\&M), as an Associate Editor of Journal of the Association of Information Systems (JAIS), and a Senior Editor of MIS Quarterly.
\end{abstract}

Jacob Tsai is a doctoral student in information systems at National Chung Cheng University, Taiwan. He spent one year in graduate study abroad at the School of Accounting and Business Information Systems, the Australian National University, Australia. His interests include research methodology and information system project and program management.

Gary Klein is the Couger Professor of Information Systems at the University of Colorado, Colorado Springs. He obtained his Ph.D. in Management Science from Purdue University.
His research interests include project management, technology transfer, and mathematical modeling with over 150 academic publications in these areas. He served as Director of Education for the American Society for the Advancement of Project Management, is a Fellow of the Decision Sciences Institute, and is an active member of the Project Management Institute. He serves on the editorial board of the International Journal of Information Technology Project Management and Information \& Management, as an SE for the Journal of the Association of Information Systems and the Pacific Asia Journal of the Association of Information Systems and as an AE for MIS Quarterly.

Stacie Petter is an associate professor of Information Systems \& Quantitative Analysis at the University of Nebraska at Omaha. She received her Ph.D. and M.B.A. in Computer Information Systems from Georgia State University. Her research interests include software project management, knowledge management, information systems success, and research methods. To date, Stacie's research has been published in outlets such as MIS Quarterly, European Journal of Information Systems, Journal of the Association for Information Systems, Communications of the Association for Information Systems, DATA BASE for Advances in Information Systems, and International Journal of Medical Informatics. She also serves as the president of the AIS Special Interest Group on IT Project Management. 


\section{Appendix A: Formatively-measured constructs in the 6 core journals: 2009 through 2011}

\begin{tabular}{|c|c|}
\hline Article & $\begin{array}{l}\text { Formatively-measured construct name } \\
\text { (Structural position) }\end{array}$ \\
\hline Burton-Jones (2009) & $\begin{array}{l}\text { - Focused immersion (exogenous) } \\
\text { - Deep structure usage (exogenous) } \\
\text { - Performance (endogenous) }\end{array}$ \\
\hline Cenfetelli and Bassellier (2009) & - SERVQUAL (exogenous) \\
\hline D’Arcy et al. (2009) & $\begin{array}{l}\text { - Security policies (exogenous) } \\
\text { - SETA program (exogenous) } \\
\text { - Computer monitoring (exogenous) }\end{array}$ \\
\hline Davis et al. (2009) & $\begin{array}{l}\text { - Joint IT competence (exogenous) } \\
\text { - Partnership-led implementation (mediator) } \\
\text { - User satisfaction (endogenous) }\end{array}$ \\
\hline Goo et al. (2009) & $\begin{array}{l}\text { - Foundation characteristics (exogenous) } \\
\text { - Change characteristics (exogenous) } \\
\text { - Governance characteristics (exogenous) }\end{array}$ \\
\hline Herath and Rao (2009) & $\begin{array}{l}\text { - Subjective norm (exogenous) } \\
\text { - Resource availability (exogenous) }\end{array}$ \\
\hline lacovou et al.(2009) & $\begin{array}{l}\text { - Optimistic biasing (mediator) } \\
\text { - Pessimistic biasing (mediator) } \\
\text { - Project size (control variable) }\end{array}$ \\
\hline Kim and Benbasat (2009) & - Consumers' trusting beliefs (endogenous) \\
\hline Kim et al. (2009) & $\begin{array}{l}\text { - Perceived risk (mediator) } \\
\text { - Perceived benefit (mediator) } \\
\text { - Perceived performance (exogenous) }\end{array}$ \\
\hline Klein and Rai (2009) & $\begin{array}{l}\text { - Buyer Strategic Information Flows to Supplier (mediator) } \\
\text { - Supplier Strategic Information Flows to Buyer (mediator) } \\
\text { - Buyer Relationship-Specific Performance (endogenous) } \\
\text { - Supplier Relationship-Specific Performance (endogenous) } \\
\text { - Buyer Trusting Beliefs in Supplier (exogenous) } \\
\text { - Supplier Trusting Beliefs in Buyer (exogenous) }\end{array}$ \\
\hline Lee and Larsen (2009) & $\begin{array}{l}\text { - Perceived severity (exogenous) } \\
\text { - Perceived vulnerability (exogenous) } \\
\text { - Response cost (exogenous) } \\
\text { - Social influence (exogenous) }\end{array}$ \\
\hline Lowry et al. (2009) & $\begin{array}{l}\text { - Process satisfaction (endogenous) } \\
\text { - Task discussion effectiveness (first-order formatively-measured } \\
\text { construct of communication quality) }\end{array}$ \\
\hline Meso et al. (2009) & $\begin{array}{l}\text { - National information infrastructure (exogenous) } \\
\text { - Governance (mediator) } \\
\text { - Social-Economic Development (endogenous) }\end{array}$ \\
\hline Phang et al. (2009) & $\begin{array}{l}\text { - Perceived usability (exogenous) } \\
\text { - Perceived sociability (exogenous) }\end{array}$ \\
\hline
\end{tabular}


Fully Mediated Effects of Formative Measures Using MIMIC Constructs / Jiang et al.

\begin{tabular}{|c|c|}
\hline Article & $\begin{array}{l}\text { Formatively-measured construct name } \\
\text { (Structural position) }\end{array}$ \\
\hline Preston and Karahanna (2009) & $\begin{array}{l}\text { - Structural systems of knowing (mediator) } \\
\text { - Demographic similarity (exogenous) } \\
\text { - Experiential similarity (exogenous) }\end{array}$ \\
\hline Rai et al. (2009) & $\begin{array}{l}\text { - Top management support (exogenous) } \\
\text { - Security safeguards (exogenous) } \\
\text { - Organizational readiness (exogenous) } \\
\text { - IT sophistication (first-order formatively-measured construct of } \\
\text { organizational readiness) } \\
\text { - Financial resources (first-order formatively-measured construct of } \\
\text { organizational readiness) } \\
\text { - Trusting beliefs of suppliers (exogenous) } \\
\text { - EPI standards efficacy (exogenous) } \\
\text { - Standards flexibility (first-order formatively-measured construct of } \\
\text { EPI standards efficacy) } \\
\text { - Standards comprehensiveness (first-order formatively-measured } \\
\text { construct of standards efficacy) } \\
\text { - Aggregated EPI Assimilation (mediator) }\end{array}$ \\
\hline Sia et al. (2009) & - Trust beliefs (mediator) \\
\hline Titah and Barki (2009) & - Intention to use (endogenous) \\
\hline Anderson and Agarwal (2010) & - Concern regarding security threats (exogenous) \\
\hline Chen et al. (2010) & $\begin{array}{l}\text { - ClO human capital (exogenous) } \\
\text { - } \mathrm{ClO} \text { structural power (exogenous) }\end{array}$ \\
\hline Choi et al. (2010) & $\begin{array}{l}\text { - IT support for KM (exogenous) } \\
\text { - Team performance (endogenous) }\end{array}$ \\
\hline Johnston and Warkentin (2010) & - Social influence (exogenous) \\
\hline Kim et al. (2010) & - IT infrastructure flexibility (exogenous) \\
\hline Lee and Xia (2010) & $\begin{array}{l}\text { - Response extensiveness (mediator) } \\
\text { - Response efficiency (mediator) }\end{array}$ \\
\hline Liang et al. (2010) & - Team climate (exogenous) \\
\hline Pavlou and El Sawy (2010) & $\begin{array}{l}\text { - IT capability in NPD (exogenous) } \\
\text { - Effective use of PRMS (exogenous) } \\
\text { - Effective use of OMS (exogenous) } \\
\text { - Effective use of CWS (exogenous) } \\
\end{array}$ \\
\hline Posey et al (2010) & - Self- disclosure (endogenous) \\
\hline Rai and Tang (2010) & $\begin{array}{l}\text { - Competitive performance (endogenous) } \\
\text { - IT integration (exogenous) } \\
\text { - IT reconfiguration (exogenous) } \\
\text { - Process alignment (mediator) } \\
\text { - Offering flexibility (mediator) } \\
\text { - Partnering flexibility (mediator) } \\
\text { - Environmental Turbulence (moderator) }\end{array}$ \\
\hline
\end{tabular}




\begin{tabular}{|c|c|}
\hline Article & $\begin{array}{l}\text { Formatively-measured construct name } \\
\text { (Structural position) }\end{array}$ \\
\hline Sila (2010) & - Adoption factors (exogenous) \\
\hline Siponen and Vance (2010) & - Neutralization (exogenous) \\
\hline Spears and Barki (2010) & - User participation (exogenous) \\
\hline Tiwana and Konsynski (2010) & $\begin{array}{l}\text { - IT architecture modularity (exogenous) } \\
\text { - IT governance decentralization (moderator) }\end{array}$ \\
\hline Chengalur-Smith et al. (2010) & - Business value (endogenous) \\
\hline Datta (2011) & $\begin{array}{l}\text { - Performance expectancy, (exogenous) } \\
\text { - Social influence (exogenous) } \\
\text { - Facilitating conditions (moderator) }\end{array}$ \\
\hline Gopal and Gosain (2011) & - Boundary spanning (exogenous) \\
\hline Hsieh et al. (2011) & $\begin{array}{l}\text { - Habitus (exogenous) } \\
\text { - Cultural capital (exogenous) } \\
\text { - Social capital (exogenous) } \\
\end{array}$ \\
\hline Ke and Zhang (2010) & - Satisfaction of needs (moderator) \\
\hline Lowry et al. (2011) & - Information privacy concerns (mediator) \\
\hline Pee et al. (2010) & $\begin{array}{l}\text { - Project phase performance (endogenous) } \\
\text { - Project complexity (control variable) }\end{array}$ \\
\hline Shin and Kim (2011) & $\begin{array}{l}\text { - IT management capability (exogenous) } \\
\text { - IT personal expertise (exogenous) }\end{array}$ \\
\hline Venkatesh et al. (2011) & $\begin{array}{l}\text { - Electronic healthcare system use (mediator) } \\
\text { - Quality of care (mediator) } \\
\text { - Patient satisfaction (endogenous) }\end{array}$ \\
\hline Wang and Haggerty (2011) & $\begin{array}{l}\text { - Virtual media skill (first-order constructs) } \\
\text { - Virtual daily life experience (exogenous) } \\
\text { - Virtuality (control variable) }\end{array}$ \\
\hline Warkentin et al (2011) & $\begin{array}{l}\text { - Situational support (exogenous) } \\
\text { - Vicarious experience (exogenous) } \\
\text { - Verbal persuasion (exogenous) }\end{array}$ \\
\hline Wells et al. (2011) & - Website quality (exogenous) \\
\hline Wells et al. (2011) & - Web Site Quality (exogenous) \\
\hline Whitaker et al. (2010) & $\begin{array}{l}\text { - IT coordination applications (exogenous) } \\
\text { - Process codification (exogenous) } \\
\text { - Internationalization (exogenous) }\end{array}$ \\
\hline Xue et al. (2011) & - Perceived justice of punishment (mediator) \\
\hline Yang et al (2011) & - Service quality (mediator) \\
\hline Zhao et al. (2011) & - Perceived process benefit (exogenous) \\
\hline
\end{tabular}


Fully Mediated Effects of Formative Measures Using MIMIC Constructs / Jiang et al.

Appendix B: Illustrative Model Information

\begin{tabular}{|c|c|c|c|c|c|}
\hline & $\begin{array}{l}\text { Mean } \\
\text { (S.D.) }\end{array}$ & Item (Loading) & $\begin{array}{l}\text { Composite } \\
\text { reliability }\end{array}$ & AVE & VIF \\
\hline \multirow{3}{*}{ Assurance } & \multirow{3}{*}{$\begin{array}{c}4.73 \\
(1.027)\end{array}$} & Ass1 (0.981) & \multirow{3}{*}{0.932} & \multirow{3}{*}{0.823} & \multirow{3}{*}{2.582} \\
\hline & & Ass2 (0.970) & & & \\
\hline & & Ass3 (0.753) & & & \\
\hline \multirow{3}{*}{ Empathy } & \multirow{3}{*}{$\begin{array}{c}4.38 \\
(0.950)\end{array}$} & Emp1 (0.698) & \multirow{3}{*}{0.828} & \multirow{3}{*}{0.618} & \multirow{3}{*}{2.317} \\
\hline & & Emp2 (0.797) & & & \\
\hline & & Emp3 (0.855) & & & \\
\hline \multirow{4}{*}{ Reliability } & \multirow{4}{*}{$\begin{array}{c}4.89 \\
(0.909)\end{array}$} & Rel1 (0.883) & \multirow{4}{*}{0.883} & \multirow{4}{*}{0.655} & \multirow{4}{*}{4.434} \\
\hline & & Rel2 (0.812) & & & \\
\hline & & Rel3 (0.821) & & & \\
\hline & & Rel4 (0.712) & & & \\
\hline \multirow{3}{*}{ Responsiveness } & \multirow{3}{*}{$\begin{array}{c}4.60 \\
(1.058)\end{array}$} & Res1 (0.878) & \multirow{3}{*}{0.932} & \multirow{3}{*}{0.820} & \multirow{3}{*}{2.205} \\
\hline & & $\operatorname{Res} 2(\mathbf{0 . 9 3 3})$ & & & \\
\hline & & $\operatorname{Res} 3(0.906)$ & & & \\
\hline \multirow{4}{*}{ Tangibles } & \multirow{4}{*}{$\begin{array}{c}4.87 \\
(1.035)\end{array}$} & Tan1 (0.879) & \multirow{4}{*}{0.939} & \multirow{4}{*}{0.793} & \multirow{4}{*}{1.478} \\
\hline & & Tan2 (0.946) & & & \\
\hline & & Tan3 $(\mathbf{0 . 8 9 3})$ & & & \\
\hline & & Tan4 (0.840) & & & \\
\hline \multirow{2}{*}{ Service quality } & \multirow{2}{*}{$\begin{array}{c}4.83 \\
(0.923)\end{array}$} & Sq1 $(0.940)$ & \multirow{2}{*}{0.931} & \multirow{2}{*}{0.871} & \multirow{2}{*}{$N / A$} \\
\hline & & Sq2 (0.926) & & & \\
\hline \multirow{3}{*}{$\begin{array}{l}\text { Perceived use- } \\
\text { fulness }\end{array}$} & & Pu1 (0.931) & & & \\
\hline & $\begin{array}{l}5.29 \\
(0.944)\end{array}$ & Pu2 (0.933) & 0.923 & 0.800 & $\mathrm{~N} / \mathrm{A}$ \\
\hline & & Pu3 (0.814) & & & \\
\hline & & Sat1 $(0.841)$ & & & \\
\hline Saticfactinn & 5.07 & Sat2 (0.901) & & 0716 & $N / \Delta$ \\
\hline Satisfaction & $(0.837)$ & Sat3 $(0.816)$ & 0.921 & 0.146 & $\mathrm{~N} / \mathrm{A}$ \\
\hline & & Sat4 $(\mathbf{0 . 8 9 3 )}$ & & & \\
\hline & & Pv1 (0.836) & & & \\
\hline Perceived value & $\begin{array}{c}4.14 \\
(0.910)\end{array}$ & Pv2 (0.888) & 0.884 & 0.727 & $\mathrm{~N} / \mathrm{A}$ \\
\hline & & Pv3 (0.832) & & & \\
\hline
\end{tabular}

\begin{tabular}{|l|c|c|c|c|c|c|c|c|}
\hline Illustrative model : Discriminant validity \\
\hline & Ass & Emp & Rel & Res & Tan & Pu & Sat & Pv \\
\hline Assurance & $\mathbf{0 . 9 0 7}$ & & & & & & & \\
\hline Empathy & 0.505 & $\mathbf{0 . 7 8 6}$ & & & & & & \\
\hline Reliability & 0.773 & 0.705 & $\mathbf{0 . 8 0 9}$ & & & & & \\
\hline Responsiveness & 0.435 & 0.669 & 0.668 & $\mathbf{0 . 9 0 6}$ & & & & \\
\hline Tangibles & 0.446 & 0.449 & 0.544 & 0.472 & $\mathbf{0 . 8 9 1}$ & & & \\
\hline Perceived usefulness & 0.401 & 0.368 & 0.522 & 0.402 & 0.439 & $\mathbf{0 . 8 9 4}$ & & \\
\hline Satisfaction & 0.533 & 0.555 & 0.665 & 0.515 & 0.358 & 0.635 & $\mathbf{0 . 8 6 4}$ & \\
\hline Perceived value & 0.356 & 0.449 & 0.446 & 0.438 & 0.526 & 0.705 & 0.516 & $\mathbf{0 . 8 5 3}$ \\
\hline Note: Square root of AVE in the diagonal
\end{tabular}

